\title{
Control Strategies of DC Microgrids Cluster: A Comprehensive Review
}

\author{
Zaid Hamid Abdulabbas Al-Tameemi ${ }^{1}{ }^{\mathbb{C}}$, Tek Tjing Lie ${ }^{1, * \mathbb{C}}$, Gilbert Foo ${ }^{1}$ and Frede Blaabjerg ${ }^{2} \mathbb{(}$ \\ 1 Department of Electrical and Electronic Engineering, Auckland University of Technology, Auckland 1010, \\ New Zealand; jxy3030@autuni.ac.nz (Z.H.A.A.-T.); gilbert.foo@aut.ac.nz (G.F.) \\ 2 Department of Energy Technology, Aalborg University, 9220 Aalborg, Denmark; fbl@et.aau.dk \\ * Correspondence: tek.lie@aut.ac.nz
}

Citation: Al-Tameemi, Z.H.A.; Lie, T.T.; Foo, G.; Blaabjerg, F. Control Strategies of DC Microgrids Cluster: A Comprehensive Review. Energies 2021, 14, 7569. https://doi.org/ 10.3390/en14227569

Academic Editor: José Matas

Received: 14 October 2021

Accepted: 10 November 2021

Published: 12 November 2021

Publisher's Note: MDPI stays neutral with regard to jurisdictional claims in published maps and institutional affiliations.

Copyright: (C) 2021 by the authors. Licensee MDPI, Basel, Switzerland. This article is an open access article distributed under the terms and conditions of the Creative Commons Attribution (CC BY) license (https:/ / creativecommons.org/licenses/by/ $4.0 /)$.

\begin{abstract}
Multiple microgrids (MGs) close to each other can be interconnected to construct a cluster to enhance reliability and flexibility. This paper presents a comprehensive and comparative review of recent studies on DC MG clusters' control strategies. Different schemes regarding the two significant control aspects of networked DC MGs, namely DC-link voltage control and power flow control between MGs, are investigated. A discussion about the architecture configuration of DC MG clusters is also provided. All advantages and limitations of various control strategies of recent studies are discussed in this paper. Furthermore, this paper discusses three types of consensus protocol with different time boundaries, including linear, finite, and fixed. Based on the main findings from the reviewed studies, future research recommendations are proposed.
\end{abstract}

Keywords: decentralized; centralized; distributed; hierarchal control strategies; consensus protocol and multi-agent system (MAS)

\section{Introduction}

The centralized power grid is a solitary method that has been used for many decades to transport energy, with power plants located widely around the country generating electricity and transmission lines conveying it to businesses and homes over lengthy distances [1]. On the other hand, distant rural regions in numerous emerging and underdeveloped countries do not even have access to the electric power provided by the power grid [2]. Aside from being economically and technically infeasible, the expansion of the main grid to a distant location is also very close to impossible [3]. To satisfy the increasing power demand and address the issues such as losses in lengthy transmission lines, dwindling fossil fuel resources, and environmental concerns, distributed generation units (DGU) using renewable energy sources (RESs) are becoming increasingly popular in recent years [4]. RESs are the most cost-effective and reliable form of electricity generation to overcome these problems and electrify distant areas [5]. In recent years, much effort has been focused on the production of electricity from environmentally friendly DGUs and their technologies throughout many countries [5-7].

Photovoltaic (PV) panels, fuel cells (FCs), and energy storage units (ESU) inherently produce DC power. On the other hand, wind turbines (WTs) that generate AC power could be more easily incorporated into the DC grid by using power conversion stages $[6,8]$. Furthermore, electric vehicles (EV), energy storage systems (ESSs), data centers, ship electrical systems, telecommunication stations, besides most of the electronic devices, including LED lighting systems, computers, phones, etc., are naturally in DC form and therefore require fewer power conversion stages, which enhance the efficiency [4]. However, the most critical defect of RESs such as PV and WT is their intermittent nature, which makes meeting load demand hard without utilizing ESSs [9]. As a result, combining ESSs with RESs is a traditional action that will necessitate a smooth and organized approach as it is scaled up. In the context of small-scale power systems, a microgrid (MG) is a set 
of local DGUs, energy storage devices, and localized loads that work together [10]. This approach has been suggested in [11] as an attractive option for combining different RESs to form an MG. A variety of MGs, including AC MGs, DC MGs, besides hybrid AC/DC MGs, has been reported in the literature, and this classification is performed according to the coupling bus type used in the system [12-14].

The DC MGs are the focus of this study because they have numerous benefits compared to AC MGs. The benefits are as follows: (i) reliable, (ii) efficient, (iii) a simple control topology, (iv) no reactive power management, and (v) no frequency synchronization [15]. These features are the primary reasons for the widespread adoption of DC MGs as a primary source of electricity to meet growing demand in isolated and small communities worldwide. Many studies have been carried out on DC MGs planning, operation, stability, and control [16]. In this regard, a hierarchal control strategy including local alongside global control layers has been used in the literature to coordinate a DC MG [17-19]. Accurate power exchange and bus voltage adjustment within acceptable limits are the MG's main control objectives at the local control level; however, there are still some challenges with individual DC MGs, such as low reliability due to the intermittent generation of RESs (WTs and PVs). In addition, islanded MGs that are substantially RES-dependent are more vulnerable to serious disruptions owing to extreme load or generation changes [8]. Such disruptions on a single unit in the system might lead to a failure of the whole system because other units can be over-stressed. Solving this issue by storage or extra generation cannot always be added, and it is not economically viable. In this regard, a microgrid cluster (MGC) indicates the process of connecting and coordinating multiple DC MGs allocated within a specific region to assist each other in case of generation deficiency in a microgrid or blackouts in the system instead of importing the main grid [20]. This way, a DC MGC can be brought together close enough to one another, enhancing flexibility and reliability by interconnecting nearby DC MGs [21].

It is important to note that the MGC approach is partially similar to the cellular approach (CA) that has been adopted in Europe in order to efficiently utilize available energy sources [22], including conventional and renewable sources, in a given region by dividing the existing traditional system of energy into several energy cells, each of which consists of the infrastructure for each of the available sources of energy [23]. It is noticed that every cell in the CA has its own cell controller that can observe and organize the local production and demand. These cells can also communicate with their neighbors. The cell coordination is similar to how MGs in a cluster are coordinated to fully use available renewable energy sources in each MG to meet demand. The cellular method, on the other hand, is a more comprehensive system than a cluster approach. Further, a cellular system is characterized by having loose connections between partially or completely self-sufficient energy cells, allowing for decentralized and independent control of the cells [24]. While in an MGC, a direct connection via a tie-line is required to exchange power among participant MGs. Furthermore, the CA focuses on regulating various energy cells that are distributed across the energy system while a close distance among MGs is needed to achieve an MGC. This article focuses on investigating all the current control technologies used in the DC MGC; as a result, the CA has not been investigated in detail.

The major advantages of an MGC include: (i) increases penetration of the renewable energy sources alongside expansion of the power supply region, (ii) increases stability and dependability of the MG in the face of generation intermittency and load variation; and (iii) increases operating efficiency, economy, and flexibility $[25,26]$.

These clustered MGs must be coordinated seamlessly to address the demand-generation mismatch between them and retain the global voltage regulation within a standard level. For example, a hierarchy control scheme has been proposed, comprising primary, secondary, and tertiary control layers. The primary layer is utilized to coordinate DGs within an MG [27]. Voltage compensation and performance improvement are dealt with at a higher level of control than the primary control, referred to as the secondary control. The tertiary control layer is responsible for managing power and optimal economic dispatch [28]. 
The multi-level control framework for the MGCs could be categorized into four different types: centralized, decentralized, distributed, and hierarchical schemes based on the communication method of MGs in a cluster, as shown in Figure 1.

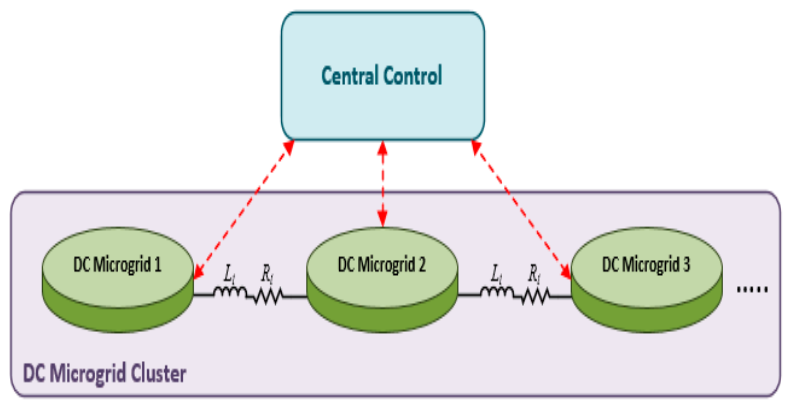

(a)

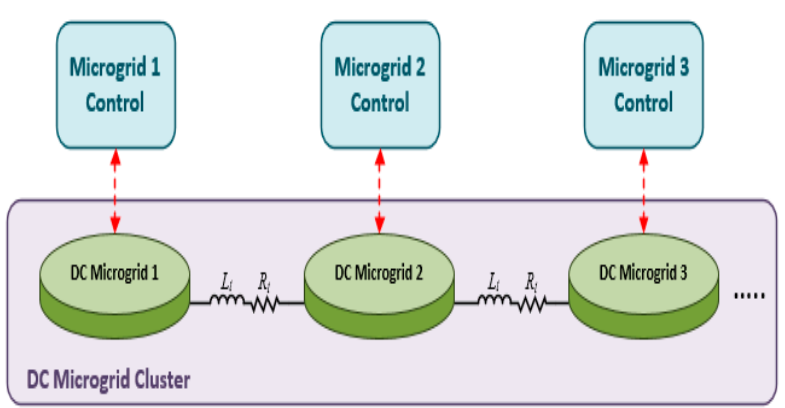

(b)

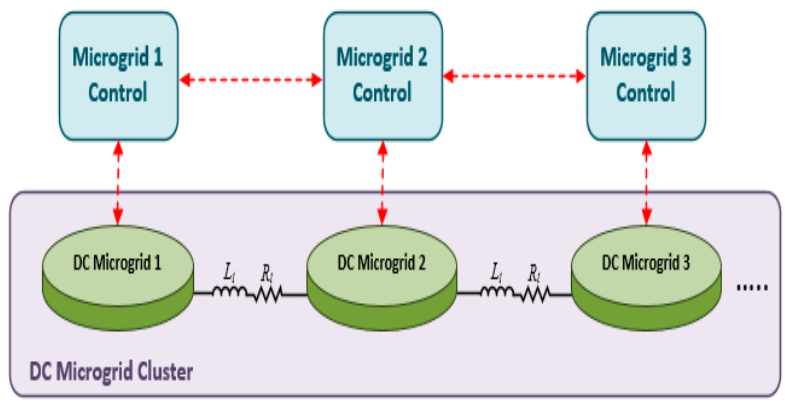

(c)

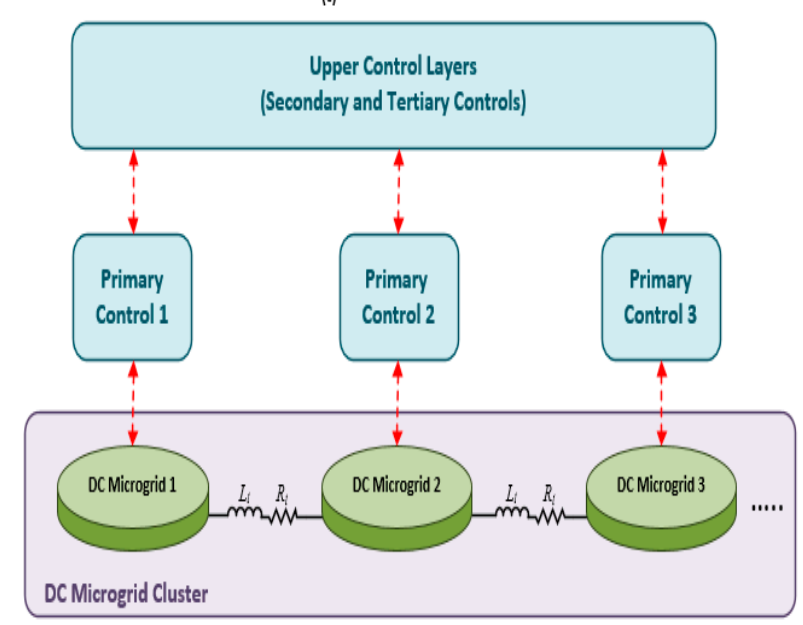

(d)

Figure 1. DC MGCs control methods: (a) centralized; (b) decentralized; (c) distributed; (d) hierarchical.

The first classification is the centralized control approaches employed to execute tertiary control, in which high bandwidth communication (HBC) links are constructed between the centralized controller and the participant agents under control. By adopting this approach, all MG data are sent to the central controller to make an adequately referenced signal available to local control layers in a cluster. In this regard, concentrated and master-slave controls have been reported in the literature as the main techniques in centralized strategies [27,29]. These control techniques have been presented in [30-32] to handle the connection of DC MGs, to achieve proper and well-organized operation. On the other hand, these control approaches are susceptible to a single point of failure (SPOF), which puts the system's stability at risk and renders it susceptible to cascading failures and eventually collapses [33]. The non-scalability of these control techniques, besides their vulnerability to a SPOF, has partially stimulated a rush of scientific research to tackle these issues.

Away from centralized control, the decentralized control strategy can send commands/orders to local control layers based on inputs from the converter or neighboring converters [34]. In this regard, three main decentralized control techniques that do not need a communication network to share orders or commands, such as DC bus signaling (DBS), conventional droop control (CDC), not including power line signaling (PLS), are reported in the literature [34-36]. Although the approaches do not need an extensive communication system or even a main centralized controller, they cannot properly supervise each converter. The requirements of high bandwidth communication in centralized control can be solved by adopting distributed control. Based on the previous discussion, the single 
use of preceding control approaches is insufficient to coordinate MGs well in the cluster. Distributed hierarchical control approach, on the other hand, enables supervised control across a low-bandwidth communication system, as well as robust voltage adjustment and proportional current-sharing by the local controller $[35,37,38]$, so it is widely adopted in coordinating MGs clusters.

Consequently, several studies on DC MG clusters application, stability, and control aspects have been performed, covering voltage regulation [39], power-sharing control [31,40,41], and the state-of-charge (SOC) balancing of batteries [42]. In addition, an increasing number of research works have been performed to address comprehensive review, particularly on the control, protection, and application of DC MGs [16,35,38,43-46]. Further, some academic research has been presented to address architecture, operation, control, and energy management regarding MGCs [33,47-49]. A comprehensive review is presented in [33] to present control aspects, power management, and protection of multiple DC MGs regarding single DC MGs. In [47], a review of the operation, control, protection, and energy management of MGCs is presented. Furthermore, the authors of [48] present an extensive overview of the application of distributed cooperative control approaches in MGs and MGCs. A complete literature overview on operation, structure, and control strategies of multiple MGs is discussed in [49]. Excluding [33], which is minorly focused on discussing DC MG clusters in general, all the mentioned works have focused on DC MGs and AC MGCs.

From the above discussion, it can be observed that a comprehensive review paper including DC MGCs developments, challenges, and future trends is required and could be of interest to the readers; therefore, a comprehensive review of control aspects and developments of DC MGCs during recent years is discussed in this paper. Motivated by the above discussion, the foremost contributions and highlights of this paper are summarized as follows:

- A complete review of various control schemes covering centralized, decentralized, distributed, and hierarchical methods in DC multiple MGs is presented.

- This paper provides a detailed comparative discussion on challenges faced with the control strategies of DC MGCs presented in the existing literature.

- $\quad$ Possible areas of research and future trends of DC MGCs are proposed.

The following is the structure of the paper: Section 2 introduces the typical architectures of networked DC MGs. A comprehensive review of various control strategies of DC MG clusters is presented in Section 3. Section 4 focuses on recent research works on the novel distributed consensus-based control strategies. In Section 5, the critical points of the control strategies are summarized and discussed. Lastly, the conclusion is presented in Section 6.

\section{Multiple DC Microgrids: Architecture}

As shown in Figure 2, a typical DC clustered MG incorporates two or more networked DC MGs with numerous forms of the distributed energy resources (DERs) including PV, WT, and FC accompanied by ESSs to face the intermittency issue and also controllable and non-controllable DC and AC loads [10]. Most of these resources generate DC electric power, besides WTs that inherently produce AC power might be coupled into the DC MG if converted [6]. In this context, two methods for interconnecting clusters and coordinating power exchange between them have been documented in the literature. DC clustered MGs with the same voltage rating were directly connected via tie lines $[13,21,50]$. This technique eliminates the need for dedicated converters used in the second type of connection, such as bidirectional DC-DC converter (BDC) and bidirectional interlinking converter (BIC) to control power transmission across MGs in a cluster. As a result, cost and converting losses are minimized; however, the tie line technique and related control strategies may not be ideal for clusters when the voltages of DC-links are dissimilar and fluctuating in clusters owing to excessive flow of power on the tie line, which might create needless transmission line losses [51]. 


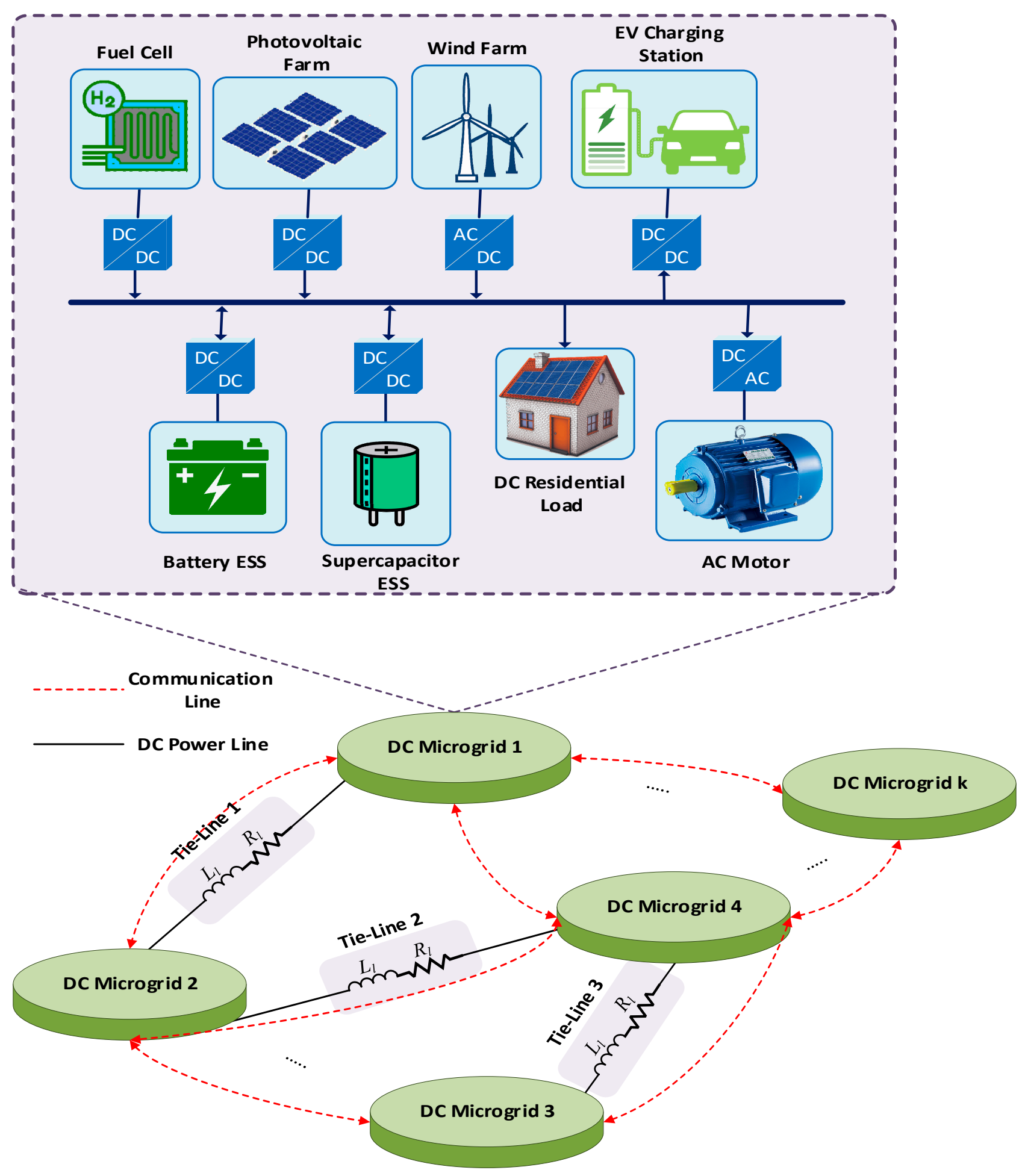

Figure 2. DC MG cluster configuration.

Another way of connection is presented in [52], where an isolated or non-isolated BDC is used to interlink DC MGs with varying DC voltage levels. It is worth noting that the isolated BIC could be in the buck-boost converter category $[53,54]$ or else a dual active bridge (DAB) converter kind in certain applications that could need isolation [51]. Such converters not only allow efficient power transfer amongst MGs with various operational DC bus voltage ratings, but they also separate MGs from one another in the presence of disturbances [55]. Both direct and interlinking converter connecting approaches for DC MGC are demonstrated in Figure 3a,b, respectively. According to these configurations, 
different control strategies based on centralized, decentralized, and distributed have been implemented to address voltage control deviations, power flow exchanges, and SOC balancing in DC MG clusters, which are discussed in detail in the following sections.

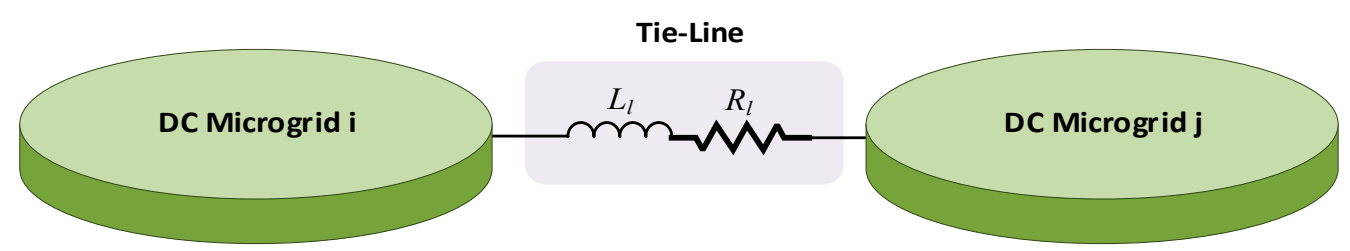

(a)

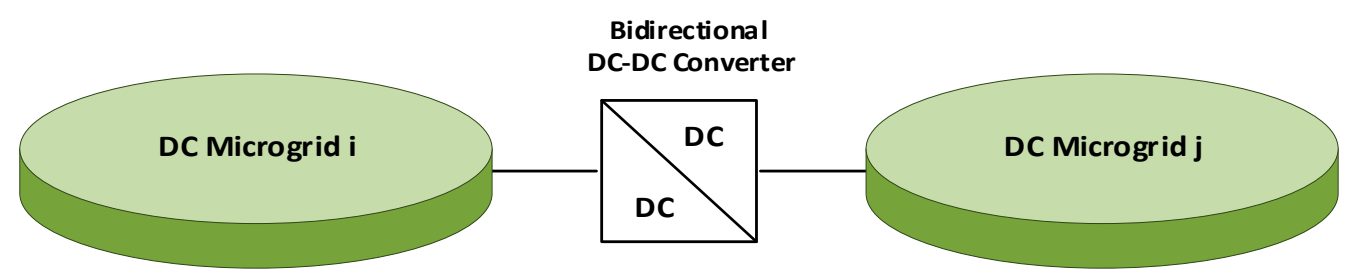

(b)

Figure 3. DC multiple MGs connection approach: (a) direct connection; (b) indirect connection.

In Figure 2, it can be noticed that all participant MGs are physically and virtually connected to their neighbors to meet the growing demand. For this design, each MG in a cluster has access to a utility grid instead of a solitary power feeder to a whole cluster, increasing the reliability of the designed cluster in providing continuous power to consumers. Back-to-back converters (BTB) are used to connect MGs to the main grid in the system. Another connection method is when the whole MG cluster is connected to the utility grid via a BTB converter.

\section{Control Strategies}

The same as DC MGs, DC MMGs can also work either in grid-connected mode or islanded mode. DC MMGs can exchange power with the utility grid in grid-connected mode, while DC voltage adjustment, without power exchange, is the most considerable control aspect in the islanding operation mode. For accurate and continuous power-sharing and to avoid power mismatch, utilizing energy storage devices is required to maintain DC bus voltage [56,57]. In this case, state-of-charge (SOC) balancing between ESSs inside each MG is challenging. When there is not a sufficient and appropriate number of energy storage devices, the distribution system operator must decide to switch some load on or off. Accordingly, the proper coordination of DC MGs in a cluster is essential to realize the system's stable and dependable functioning. In the literature, four types of control strategies, including centralized, decentralized, distributed, and hierarchical control, have been proposed to address these issues. Droop control could be employed for DC-link voltage stability and power management between DERs inside each MG and between networked DC MGs [58]. Although they have simplicity in implementation because of the non-use of communication links, they may cause DC voltage variations; therefore, utilizing second and third control layers based on previous control classifications is inevitable. However, not all tasks could be accomplished in a distributed, centralized, or decentralized way as current energy systems become more sophisticated and demand more intelligence, particularly when the system encompasses an intricate decision-making mechanism [33]. As a result, a hierarchy control approach is used to address such issues. These four type control strategies are summarized in Figure 4. This figure depicts all control techniques used in the literature. These methods are discussed in detail in the following subsections to 
provide a clear picture of their merits and demerits with some solutions as proposed in the literature. Then, the best control strategy to be adopted in future research is recommended.

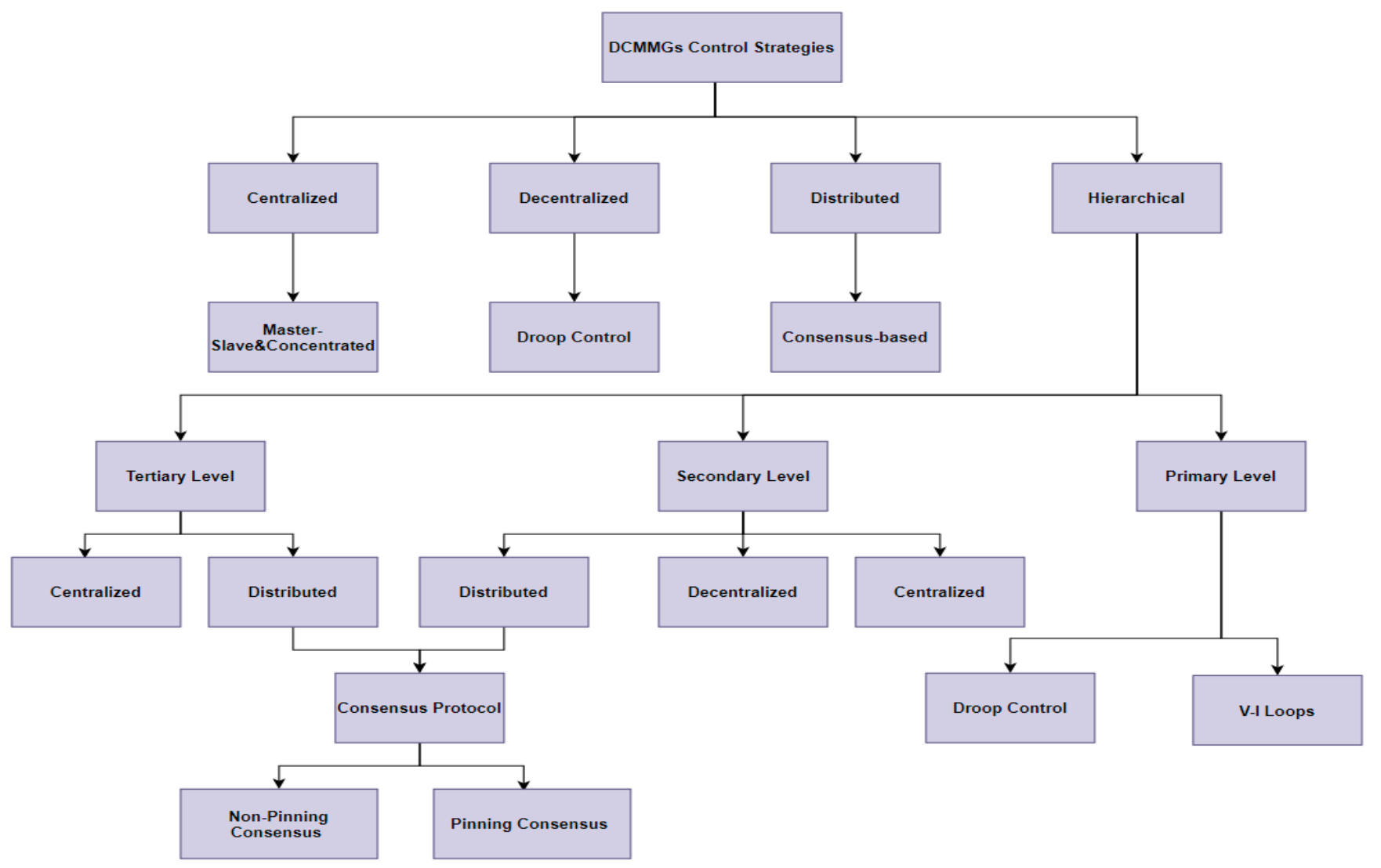

Figure 4. DC MG cluster control strategies.

\subsection{Centralized Control Methods}

The centralized method refers to the process of sending all available information of the participants' units in the system to the central control unit (CCU). This information transmitted via bi-directional communication links is analyzed in CCU, and then suitable decisions with associated commands are delivered back to the controlled devices $[59,60]$. Based on the centralization concept, this technique is employed to handle all the MGs in the cluster via a chief controller, as shown in Figure 1a, making it easy and convenient [61]; thereby, it is adopted in some research studies in the literature. For example, the authors of [31] employed a central proportional power management control approach to manage and accomplish proportionate power exchange across interconnected microgrids with dissimilar voltage levels. In this study, an IC is used to connect two DC MGs. DGUs engage in power-sharing under the suggested centralized method, whereas ICs are centrally controlled to transfer energy across clustered MGs. By implementing this control technique, power-sharing across MGs is implemented in parallel, which may result in power losses on tie-lines; however, this issue is solved by adopting a novel power-sharing in [5] and a power-sharing algorithm in [62].

Another algorithm for power-sharing was proposed in [62] to enable islanded DC MG clusters' effective and reliable functionality. The suggested method estimates the amount of power to be shared based on the status of all DERs in the DC MG, and the DC MGC fairly distributes power. Even though it can achieve adequate power exchange on tie-line and voltage control of the clustered MGs, high bandwidth of communication is required. Moreover, it has not been tested with a large cluster to assess its effectiveness. Unequal voltages can cause some significant issues in the system, especially if it is subjected to load-supply uncertainty. A supervisory control approach is proposed in [41] to coordinate 
two DC MGs with unequal voltage levels interconnected with the means of a bidirectional flyback converter. Although the proposed configuration is tested under several changes in the load demand and solar irradiance, power distribution amongst coupled ring MGs is achieved, whereas keeping their respective voltages within standard levels is realized, and the system remains stable.

Further, the authors of [63] proposed a cloud-based coordinated control approach for centrally controlling DC MGs within a cluster. This control scheme is verified to be operated efficiently for both standalone and linked MGs under different load and PV generation conditions. The suggested method enables efficient resource use in the MG cluster, increasing the system's efficiency and perhaps lowering reliance on energy storage devices; however, if all MGs have sufficient power to cater to load demand, excess electricity must be exported to the main grid, which was not deemed an economically viable alternative in the research. Although the proposed techniques in $[41,63]$ achieve good performance under load-supply uncertainty, they have not been tested with faults conditions. Therefore, in [32], a centralized control strategy is presented for coordinating the participant MGs that are coupled via bidirectional DC-DC converters with a view to managing bidirectional power exchange amongst the DC MGs under a variety of operating scenarios and fault conditions while keeping constant DC voltages in both DC MGs.

It is worth noting that processing and collecting a large amount of data in one location may cause the system to suffer from a single point of failure. Furthermore, this technique cannot be expanded to large-scale networked MGs due to a complex communication network requirement. Another issue is that the system's cost is increased because of the usage of high-bandwidth communication lines. Further, in the references mentioned above, classical tuning methods have been used to tune PI-controllers of control strategies that may be vulnerable to significant disturbances in the system. This problem has been addressed recently in [64] by using metaheuristics algorithms to optimize PI-controllers and fuzzy logic combined with PI-control to enhance its performance. Generally, the centralized control strategy is not very effective to be applied on a large-scale system due to the drawbacks discussed earlier.

\subsection{Decentralized Control Methods}

The decentralized control, which is depicted in Figure 1b, is another type of control strategy utilized in the control of MGs cluster. In this approach, each MG uses its own local measurements, and control actions are verified through local controls without any communication links. As a result, adding or removing an MG has no impact on the activities of other MGs in the system [65]. Several studies have been conducted to exploit the lack of dependence on communication links to transform information among MGs. For instance, a coordinated control scheme with an intelligent power function has been proposed in [66] to achieve the system's reliable and stable functionality of the DC MGs. Fuzzy droop control with voltage feedback compensation is implemented in the ESS, allocating load among storages, thereby enhancing DC bus voltage and power exchange amongst MGs. This method is featured by fast response speed and smooth switching mode among MGs, improving system stability; however, circulating currents with their associated power losses have not been considered in the study. Further, heterogeneity of energy resources and faults conditions have not been considered to validate this technique's effectiveness efficiently.

A decentralized control method was proposed in $[13,67]$ to achieve the proper coordination control of networked MGs, which are interconnected through tie-line. This presented technique manages power flow among MGs in the cluster and regulates DC-link voltage within acceptable limits under different load variations, which is proven effective. However, it is found that it has low responsivity to huge load variations as well as circulating currents in tie-line that result from unwanted power transferred among participant MGs in the cluster are not controlled, which indicates that high power losses may occur; therefore, the authors of [5] propose a new algorithm to control power-sharing in multiple 
MGs. During a discrepancy of load and generation, this control technique shares power requirements amongst interconnected MGs. Therefore, circulating currents amongst DG units will be prevented when no power exchange is required. Although it is featured by the minimization of circulating currents, power-sharing priority, and autonomous working of each MG, solar power and load fluctuations simultaneously have not been considered in this study to validate the effectiveness of this technique.

A cooperative control system is presented in [68] to enable the stable and reliable operation of autonomous DC MGC in situations with high penetration of RES in MGs. On the one hand, this technique allows for appropriate voltage adjustment and control of the tie-power line's flow among clustered MGs, which can contribute to reducing tie-line power losses. On the other hand, the regulation of power flow inside individual MGs was not optimally achieved because a fixed value of the tie-line current reference is adopted in this work, so internal power losses are supposed to occur. Further, the direct interconnection of microgrids in the cluster may cause obstacles in connecting more MGs out of/within a geographical region in case of emergency scenarios. An innovative decentralized voltage management method is suggested in [51] to effectively coordinate the flow of power amongst DC MG coupled by two BDCs to overcome the long-distance among microgrids in the cluster. The proposed technique can transmit power across clusters while controlling ESS functioning and satisfying load demand in each cluster, reducing transmission line losses among the DC MGs. Nevertheless, this technique can only decrease the power losses over tie-line between microgrids while ignoring the internal microgrid losses. It has not, however, taken into consideration the stability problems that might arise when two BDCs are connected to the common transmission line.

To coordinate unequal voltages, DC MGs coupled by dual active bridge converters, power control, and management strategy (PCMS) is introduced in $[69,70]$. In contrast to [68], this control technique can be used to manage power flow not just across the DC MG cluster but also inside a single MG, which can improve system reliability and resource utilization. Although the presented method is featured by its simplicity and reliability in using bus voltages to shift modes instead of dedicated communication lines, expanding this technique across multiple MGs is proved challenging. The previous studies ignore the nature of DGs in microgrid (MG), so the efficacy of the previously presented decentralized control strategies may not be effectively validated. The authors of [71] suggest an adaptive V-I droop technique for decentralized control of an autonomous DC MG's PV/battery-based distributed architecture. The design is made up of clusters of nano grids, each of which may function independently while still sharing resources with the rest of the community. The suggested approach combines the benefits of the current architectures, such as modularity, scalability, and decreased losses, with strong, coordinated, and non-communication decentralized control, making it ideal for electrifying rural areas in emerging countries; however, due to the lack of interlinking converters among microgrids, they must be operated at the same voltage level, and this may prevent adding more microgrids to the proposed architecture. Additionally, these microgrids are supposed to be near to each other since a mechanism to communicate data among them is not available.

A novel decentralized control technique based on the P-controller that adjusts the efficient droop coefficient is proposed in [7] to concurrently achieve reasonable voltage adjustment and precise load sharing of the clustered MGs. The circulating currents that occur from various loading situations on the DC bus of each region in the system are minimized by adopting this innovative technique, resulting in less needless power loss. This technique considers the long-term impacts of various line settings and loading circumstances on system performance. However, the suggested technique's primary shortcomings are as follows: (i) it does not remove all vacillations in the DC-link voltage, (ii) the flow of power over tie-line does not precisely drop to the lowest value, and (iii) plug and play (PnP) functionality are not accessible in the approach, which means that any system disturbances 
are not prevented. Thus, it may not be suitable for complicated MGs owing to all the problems.

The main defects of [7] are addressed in [72], where a decentralized PnP voltage/current controller is suggested to coordinate DC MG. Each of which is made of grid-forming and grid-feeding converters and can concurrently realize voltage support alongside the functions of current feeding based on the local measurements. It can be noticed that although both PnP capability and global closed-loop stability of clustered MGs are guaranteed, the realization of optimal power-sharing and the minimization of power losses are not considered in this study. The researchers of [40] suggest a new harmonic-based control technique to control hybrid AC/DC sub-grids. In this study, bidirectional DC-DC converters (BDCs) and parallel bi-directional (ICs) are used to couple DC sub-grids and both sides in the hybrid MGs, respectively. The suggested technique eliminates needless power exchange between the two sides and provides a precise power allocation among parallel BICs according to their ratings. This method is also featured by lower circulating currents between two sides of the cluster, which can reduce the power losses. The converters run more cost-effectively and flexibly utilizing this technique but are also spared from overstressing due to spurious loading, leading to well-maintenance and further resilient operating hybrid MGs; however, the internal power losses inside AC MGs and AC microgrids have not been considered. Further, the nature of DGs employed in this study is not considered, so the proposed method may not be efficiently validated.

To summarize, the suggested control methods have a communication-free connection, a reduced cost, and no communication latency; however, the main disadvantages are that they do not support PnP functionality, except for [72], which makes them unsuitable for complex DC MGs due to losing communication links among them, alongside a lack of data on other systems; as a result, they may not be a suitable choice for the upper control level. Furthermore, the authors of the abovementioned references focus mainly on reducing power losses among microgrids in a cluster without considering the importunacy of power losses minimization inside each MG. Moreover, it does not include SOC balancing through decentralized control strategy in networked DC MGs. Finally, most of the discussed studies in this section ignore the nature of DGs inside each MG, reducing the reliability of this control method in controlling MGs cluster in the real-life scenario.

\subsection{Distributed Control Methods}

To overcome the weaknesses of decentralized and centralized control approaches, distributed control technique is suggested in the literature to address DC-bus voltage control in addition to power-sharing of DC MGCs. In contrast to the centralized method, the distributed one works with one-way communication networks, and MGs or DERs use their own information and the information obtained from their just immediate neighbors, as depicted in Figure 1c. Based on such features, several studies have been conducted in recent years to use this control strategy in coordinating DC MGs in the cluster. For example, a distributed hierarchical control framework proposed in [21,73] is to accomplish the efficient and reliable functionality of DC clustered MGs in the system. A central controller for autonomous operation of each MG in a cluster to amend the DC-link voltage of the DC MGs in the cluster, as well as a distributed controller for overall connectivity among MGs to govern power flow among them depending on their levels of charge, are included in this proposed scheme. Even though this technique effectively achieves voltage adjustment and power exchange management, the influence of communication latency on the suggested method's performance is evident, as demonstrated by the results in [21]. Additionally, power losses and the realization of balanced regulated SOCs have not been included for the sake of simplicity, indicating that the model may not be trustworthy for real-world applications.

According to [74], the control method employed in [21] has been modified to mitigate the fluctuation of energy generated from DGUs and regulate the power balance of the source load. It is updated to make use of the reference's information obtained from 
the tertiary control layer, and it adjusts MG voltages to reduce the discrepancy between the states of charge of the used batteries and their references. To manage the output power of the ESS according to the values of SOCs, the output voltage of the ESS must be proportionate to the values of SOCs. In [42], the SOC-featured distributed tertiary control technique is presented to coordinate all ESSs in a cluster and automatically allocate the power in each MG's ESS depending on their rates. Because of the various capacities of ESS in MGCs, the control method, which is based on the consensus algorithm, can quickly bring the SOC and the output current of each EES to a consensus, both in charge and discharging phases; however, this design is extremely sensitive to any emergency scenario that influences its convergence, as it depends on the ESS adjustment factor to achieve convergence.

A distributed tertiary control technique that behaves cooperatively is proposed in [75] is to regulate the powers transferred among the sources of interlinked MGs and modify the voltage set point of individual MG in a cluster based on its local load. While this technique has been proven to improve load sharing and fault resilience in MGs, the unanticipated disparity amongst terminal voltages can produce a circulating current even with no need for power-sharing, which is not addressed in this study, so potentially increasing tie-line power losses. This problem is addressed in [76] by proposing a novel cloud-based strategy to cope with the optimum power routing problem in the clustering of DC MGs, which can control DC-link congestion and reduce power losses in the cluster. The suggested strategy's performance is independent of network architecture, and it may be used to both radial and non-radial power grids of various sizes, as well as any number of MGs. Further, a twolevel distributed control framework for an MGC is designed in [34], with a droop control working at the local control level and a consensus algorithm running at the global level. In both dynamic and stable situations, the consensus-droop-based control approach has been found to be capable of regulating the DC-link voltage with precise current sharing across several DC converters. It can be noticed that the information of all participant units in the system needs to be transferred to the global control layer to send a proper signal reference to the local control layer, and this requires a complex communication network, so the costs of communication construction are increased. Further, the proposed methods in $[34,76]$ have not been examined under some operating conditions such as RES/load uncertainty, and fault conditions, communication delays to efficiently assess their effectiveness to be applied in real-life scenarios.

The authors of [15] present a distributed two-level tertiary control scheme for adjusting the set-point voltage of each MG and balancing the loads across all coupled sources in the MGC. Global voltage regulation and tie-line power flow management are performed via a cooperative method. It was observed that this technique allows for PnP functionality and is resistant to physical and cyber-attacks, making the system more stable and reliable. Although it is featured by employing the pinning idea, which can reduce communication construction costs and make the system scalable, on the flip side, the diversity of energy resources is neglected and replaced by a rectified AC-sources coupled to DC-link through buck converters and the ignorance of RES uncertainty are the main defects associated with this approach. Furthermore, a distributed cluster cooperative approach for clustered DC microgrids over two-layer switching network topologies is proposed in [77], where slave-DGs can share data within individual MG in the slave control layer. In addition, the master-DGs (pinned DGs) are permitted to share data among MGC in the master layer, reducing communication burdens significantly because communications are only restricted among the pinned DGs. The voltages of all DGs may be controlled to an acceptable range in this manner, and precise current exchange could be achieved not only inside individual MG but also between several MG clusters. This approach manages and regulates participating DERs in the cluster with greater efficiency, scalability, reliability, and resilience. In addition, the control performance of clusters in load fluctuations and PnP scenarios has been verified. The last two references are featured by reducing communication costs in the system based on adopting pinning consensus protocol which is discussed in detail in Section 4.2 and is 
considered an excellent solution to address the communications obstacles in the previous references, especially [34].

It is important to mention that most of the above studies ignored the nature of DGs used in a cluster, so their proposed control techniques have not been examined with the uncertainty of RES. In this regard, a MAS-based coordinated power control technique with virtual inertia (VI) is suggested in [25] to coordinate FC-based DC MG clusters. To suppress the disturbances of DC-bus voltage, smooth FC output power, and regulate a flow of power in the DC MG, the local control layer including a maximum power point tracking (MPPT)VI dual modes control technique, a new droop control method, and an inertia emulation control method is used [25]. The global layer achieves coordinated power control and global voltage regulation of clustered MGs. It is worth noting that this technique ensures SOC consistency control, abrupt load response, and PnP capabilities. Until this point, a linear consensus algorithm is used to coordinate MGs in a cluster that may not always be able to face abnormal conditions. This issue is solved by adopting finite and fix time consensus algorithms, as explained later in Section 4. Further, the authors of [78] proposed a distributed hierarchical control system and the corresponding cluster consensus-based multilayered event-triggered control approach. It consists of three control stages that enable current distribution alongside voltage regulation of ESSs between individual MG and the whole MGs cluster. This method collects the characteristics of a clustered power network and efficiently delivers proper references to the control scheme. The suggested distributed scheme has the potential to lower communication costs while also ensuring adequate current sharing and voltage management; however, the diversity of energy resources has not been considered in this article, so the efficacy of the suggested technique has not been tested under the uncertainty of RESs. Diode conduction and reverse recovery losses should also be addressed since they might result in low operational efficiency. Reduced device stress should also be taken into consideration to minimize the cost of maintaining converter integrated ESS.

A new direction has been adopted to enhance the control performance of MG clusters by replacing classical controllers with predictive ones, and this has been performed in [79], where a novel control approach based on a predictive function controller (PFC) is used to coordinate DC MG clusters under any load variation condition. Using this control technique, the loading gap between neighboring MGs is therefore employed in an updated policy to modify DC MG voltage set points to enhance power flow and alleviate the mismatch. It can easily be shown that the undesired overshoots in DC-link voltage with the PFC-based tertiary controller are lower than with the traditional PI controllers, which significantly reduces device stress and maintenance expenses. From the previous references, many issues have been pointed such as the heterogeneity of energy sources being ignored, excluding $[25,73,79]$ and uncertainty in renewable energy and actual load variations, have not been considered. On the other hand, it also found that these papers provide a distributed control system depending on the linear consensus concept. In this view, with an indefinite settling period, agents can attain a consensus in an asymptotic convergence manner [80]; however, because MGs are susceptible to quick disruptions owing to the intermittent renewable sources (PV and WT) and abrupt load changes, asymptotical convergence controllers might not even be suitable for handling the often-occurring operational conditions [81]. Furthermore, this impact is particularly noticeable in multiple MGs clusters, where there are many discontinuous DERs and loads, making the necessary communication architecture considerably complex.

\subsection{Hierarchical Control Methods}

Many studies have suggested the concept of hierarchical control to address control challenges that arise from the integration of DERs into an MG and coordinate MGs in a cluster $[47,82]$. This approach entails several layers of control, which improves the MG's flexibility and efficiency. The primary features of this strategy are the capability to categorize the MG control system into multiple levels to provide high control reliability and 
smooth operation in grid-connected alongside island modes [43]. The first control level oversees the preliminary power-sharing control, current, and voltage regulation of the converters. Any voltage deviation that may result from this control layer is addressed at a higher level of control than primary control, referred to as a secondary control. Tertiary control is accountable for the functions of optimum energy management, including optimization of the available energy resources, power flow management, and economic dispatch $[49,83]$. This concept is presented to coordinate the clustered MGs depending on a consensus algorithm commonly used in the literature. Figure 5 depicts the main tasks in each control level of the hierarchy scheme.
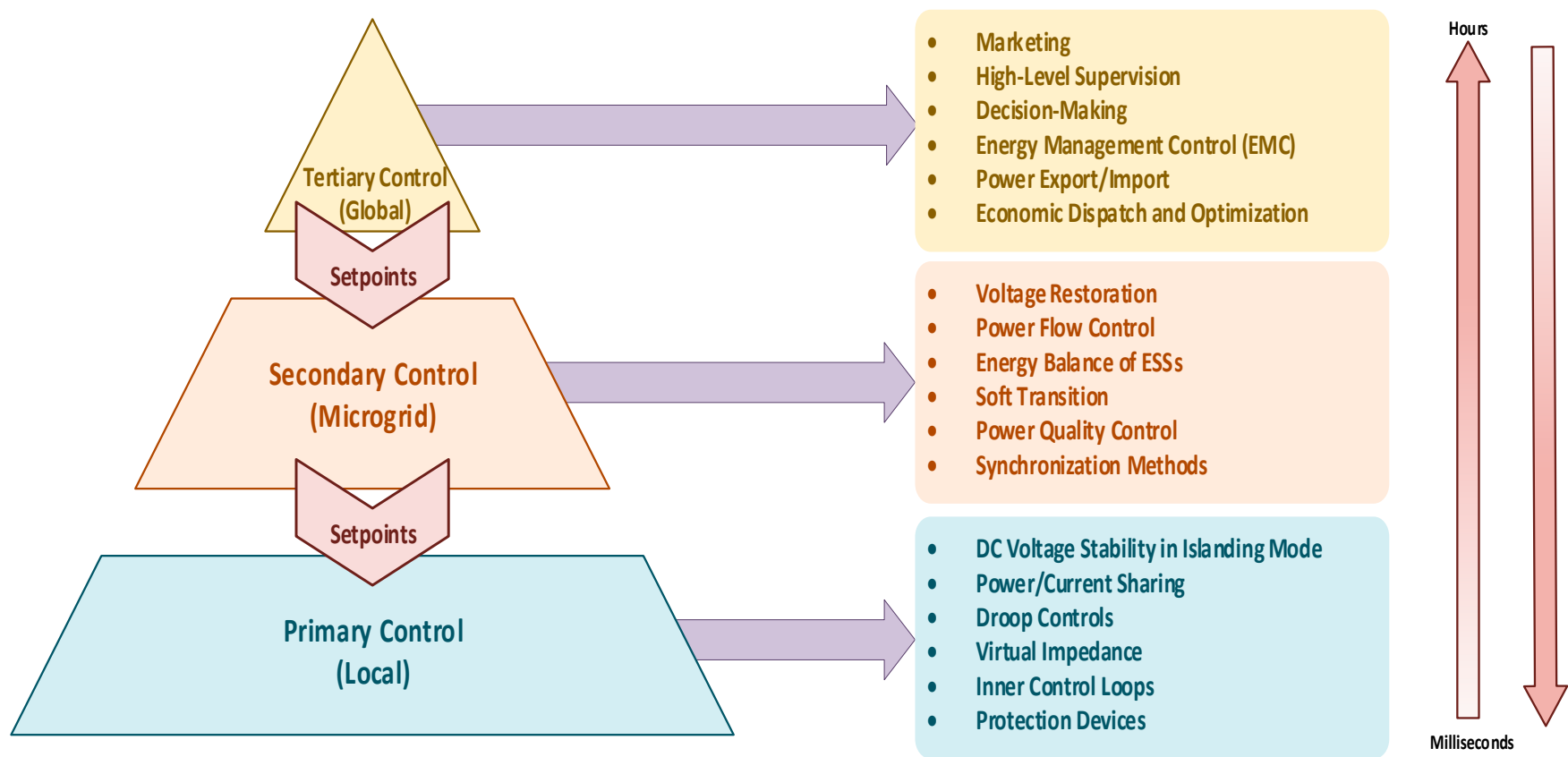

Figure 5. Hierarchical control scheme.

\subsubsection{Primary Control Layer}

The primary control layer denotes the first control level of the hierarchy control approach employed to control each MG's DC-link voltage [50]. The main aim of this layer is to adjust both of output current and voltage of the DC-DC converters in an MG. Because it relies on only local variables, the required performance of the system cannot be achieved because of a lack of information about the units in the other MGs. Consequently, the top-level controllers must be communicated with the primary control layer to accomplish properly referenced signals to the primary level, which may realize good coordination of DGs in an MG [33]. To be more specific, it executes control actions over converters whenever it obtains the set-points provided by top-level controllers. Although there are numerous control approaches such as droop control, DC bus signaling, the fuzzy logic controller has been applied to the primary control layer-its use of the local data alongside maintaining voltage stability has been studied in the literature-droop control with current and voltage loops, respectively, is commonly adopted in this level [35]. It allows powersharing without the need for communication in a parallel linked source arrangement, which is regarded as one of its most inherent benefits. As a result, communication-related fault concerns are excluded [84]; however, this method suffers from the trade-off between power exchange and DC-bus voltage adjustment [4]. Further, this technique may not be suitable for all DGs types in the MGs; thereby, the primary controllers can take on various forms, such as charge/discharge control for energy storage systems, including MPPT for both PV arrays and WTs based on input sources for the converter modules [79]. As previously mentioned, the droop control method depends on the droop coefficients 
selection so that this method control could be divided into two strategies: traditional and adaptive approaches; however, DC-DC power converters used in the inner loops of each microgrid need to be discussed.

\section{A. DC-DC Power Converters}

DC-DC converters are essential components in DCMGs since they connect various types of energy sources and loads to a common DC-link in the system [85]. Depending on the primary energy resource type, several types of DC-DC converters may be used for each energy unit [17]. When renewable energy, such as solar panels, is employed in MGs, grid-feeding converters are employed as the link to accomplish current feeding for the microgrid depending on the MPPT algorithm's reference. Grid-forming converters, on the other hand, are employed as the link between energy storage units (ESUs) and the DC-bus to support the voltage of an MG utilizing a voltage-current (V-I) double-loop controller [72]. It is worth mentioning that at least a single grid-forming/grid-supporting converter is required to form the MG's voltage. The MG's voltage is established at its reference value by using the control system. By adjusting the converter's current, an inner current controller can increase the control system's dynamics. The output current of the DGs is allocated depending on the line resistances in the event of several gridforming converters in an MG [17]. Regardless of the converter type, the upper control layers are required to coordinate these converters by sending a suitable signal to a primary control layer to realize global voltage regulation alongside proper power-sharing amongst participant MGs in a cluster, as explained in the following subsections.

\section{Droop Control Strategies}

Two types of droop control methods have been used in the literature for the DC MGs cluster, as discussed in the following subsections.

\section{B. Traditional Droop Control}

The traditional droop control is classified as a common decentralized method for achieving power-sharing by using virtual resistance. The droop coefficient has a direct relationship with power-sharing precision and voltage stability [86]. Where the better accuracy of current distribution and the larger voltage deviations occur, the higher the droop coefficient, and vice versa, which implies the droop coefficient value selects the controller's intrinsic trade-off [36]. This control method is mostly used in coordinating DGs in each DCMG within a cluster, as shown in $[27,60,78,80,87,88]$. In each microgrid within a cluster, a virtual resistance loop that embodies droop control is constructed on the outer loop of the local control layer, which allows various sources to be connected in parallel, hence sharing load current among units in the system. By utilizing this approach, parallelconnected VSC-based DGs may be managed effectively to distribute power among the available sources. As a result, the circulating current that is generated because of physical differences between converters and line impedance is minimized [31]. The Voltage-current droop technique produces an accurate voltage reference for the internal loop of voltage, which may be stated in Equation (1) as follows [4]:

$$
\begin{array}{ll}
V_{d c}^{r e f}= & V_{d c}-I_{o} \times R_{d} \\
R_{d}= & \frac{5 \% o f V_{d c}}{I_{o}}
\end{array}
$$

where, $R_{d}$ and $I_{o}$ indicate the droop coefficient alongside the current of the paralleled converter, respectively. Furthermore, $V_{d c}$ and $V_{d c}^{\text {ref }}$ imply the output voltage of the DC-link and the reference voltage of the MG, respectively.

Nevertheless, in certain circumstances, due to changes in line impedance factors besides other considerations, the droop gain might be chosen to be excessively large, resulting in a significant drop in the operating point of the voltage of DC-link and an increase in the voltage deviation. Conventional droop control is frequently unable to take 
both voltage adjustment and load distribution into consideration at the same time $[35,61,89]$. Because of this, to achieve proper voltage regulation, the function of droop control must be modified, as shown in Equation (2) [61].

$$
\begin{gathered}
v_{k, i}^{*}=V_{k}^{r e f}-d_{k, i}^{*} P_{k, i}+\delta v_{k, i} \\
d_{k, i}=d_{k, i 0}-\delta d_{k, i}
\end{gathered}
$$

where $\delta_{v k}$ refers to the value of voltage correction, which can be calculated by computing the variance between the operating point of the voltage of DC-link $\left(v_{k, i}^{*}\right)$ and its reference $\left(V_{k}^{r e f}\right)$ and then it is passed to PI-controller. Furthermore, $d_{k, i}, \delta d_{k, i}$ and $P_{k, i}$ denote the modified droop coefficient, droop correction coefficient, and amount of power in the system, respectively.

Another improvement has been made in [7] that is based on a P-controller that can amend the efficient droop coefficient to provide simultaneously reasonable voltage adjustment and adequate load sharing, and it is expressed in Equation (3).

$$
V_{d c}^{r e f}=V_{d c}-I_{o}\left(R_{d}+R_{l i}\right)+K i I_{o}
$$

where, $R_{d}, I_{0}, R_{l i}$ and Ki denote the droop coefficient, output current of the converter, line resistance, and the gain of the i-th converter's feedback proportional controller, respectively. Moreover, $V_{d c}$ and $V_{d c}^{r e f}$ refer to the DC-link's voltage and the MG's reference voltage, respectively.

Furthermore, using the adaptive fuzzy technique, a novel droop control is developed, and the extra control loop is employed to build a voltage reference for enhancing the stability of the system alongside power distribution accuracy [90].

\section{Adaptive Droop Control}

An adaptive droop control technique is proposed for the MMGs' DC connection interfaces to flexibly regulate the power transfer amongst individual MG [91]. Even though the droop control approach has drawn much attention in the literature, it may not be the appropriate solution for RESs that use droop control and are constantly engaged in voltage support. When feasible, it is usually preferable to harvest the maximum available power from RESs utilizing the MPPT method [50]. Additionally, effective techniques for recovering the SOC of the coupled battery inside the MG are presented in [92]. In this regard, an adaptive droop method has been presented in $[93,94]$ and used to coordinate DGs inside MG within a cluster based on their batteries' SOC. The authors of $[21,50,79,92]$ adopted this control method to balance the batteries' SOCs in the system, and this can contribute to enhancing power exchange among MGs. Due to the fact that renewable energy resources are directly influenced by environmental conditions, the PV system is usually controlled at MPPT mode for efficient utilization of renewable energy; however, any extra power should be passed to the battery to be charged; otherwise, the charging process must be stopped to avoid the possibility of the battery overcharging. To keep the stability of DC voltage, MPPT-VI dual-mode control method is used in [25]. The authors of [25] propose a new adaptive droop control technique based on the time-varying droop coefficient to coordinate the battery packs in the cluster. By adopting both new control techniques, the system will be able to resist any disturbances that may occur because of the RES intermittency. Figure 6 depicts the adaptive control technique used in the DC MG cluster. 


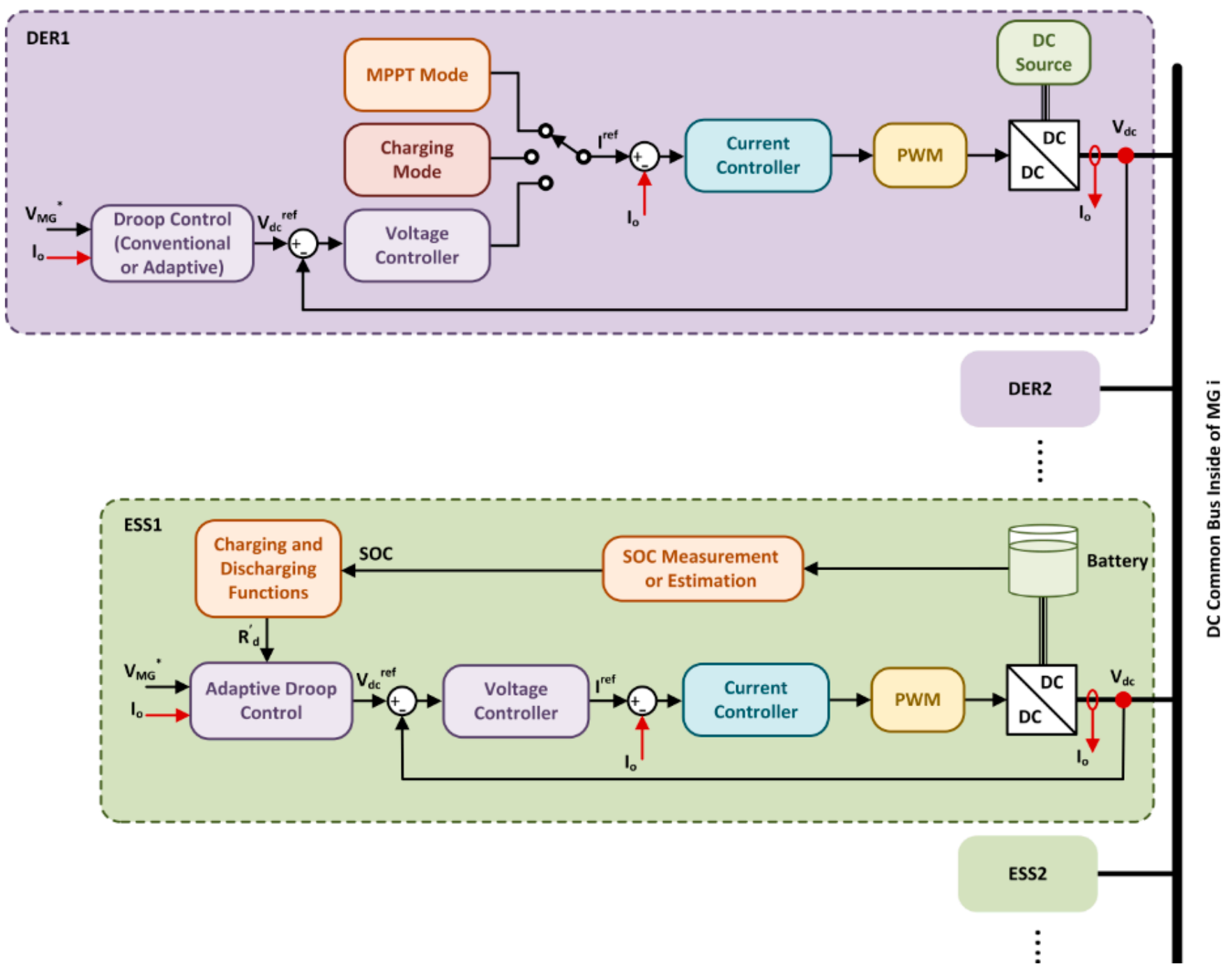

Figure 6. Adaptive droop control in DCMGC [50].

The previous discussion shows that the utilization of droop control techniques is dominant in the primary control level of the DC MG cluster, with few of them focusing on the adaptive control method (see Figure 6); however, both control techniques have not been examined under real-time measurements of RESs to validate their effectiveness.

\subsubsection{Secondary Control Layer}

The secondary layer is the second control level of the hierarchical control strategy, which plays a significant role in managing MG and MG clusters. From the previous discussion about droop control, some issues have been noticed, including voltage deviation and current sharing among DGs units inside individual MG; thus, a secondary controller is required to overcome such problems [78]. This level's goal is to give the local controllers in each MG reference points of voltage and current. By realizing voltage adjustment and current sharing, the local controller's performance is improved. Increasing the MG's power-sharing capacity also helps to enhance the system's overall power quality [35]. A secondary control layer could be implemented in either centralized, decentralized, or distributed way with a common objective which is a voltage restoration of MG [46]. A centralized voltage secondary control could be employed to return the voltage of the DClink to its standard level. This approach, which is customarily realized with conventional PI-controllers, can eliminate voltage variations inside each MG in a cluster by transmitting proper set-points to the local control layers [64,92]; however, because of the drawbacks 
of the centralized controller discussed previously, it may not be preferable in the DC MG cluster. Decentralized secondary control, which has been presented in $[7,13,68]$, can be used as another way to overcome the problems of the previous control, but it can properly manage all connected MGs in a cluster, as explained in Section 3.2. It can be noticed from the previous discussion in Sections 3.1 and 3.2 that both control techniques are not recommended to be adopted in the second control level; therefore, it is decided to implement a distributed secondary voltage control approach based on two possible approaches, including non-pinned $[21,50,73,74]$ and pinned distributed consensus-based algorithms $[15,78,81]$. Regarding the first approach, a dynamic consensus strategy with different time-boundaries has been performed in the literature, as thoroughly explained in Section 3 [50]. This method can perform all the functions of the centralized controller while reducing computation and communication expenses and being robust to failures or unidentified system characteristics. It also has increased adaptability and dependability. Noteworthy advancements were achieved in evolving distributed controllers for interconnected DC MGs, which can work in either off-grid or on-grid configurations. To achieve the key objectives, non-pinning distributed secondary controllers must be capable of achieving both effective voltage adjustment and proportionate load sharing across the local DGs while remaining resilient to communication connection unpredictability as well as cyberattacks and other threats [87]. In this technique, the non-pinning distributed protocol at each agent can be expressed in Equations (3) and (4) as follows:

$$
\begin{gathered}
V_{i}^{a v e}=\sum_{j \in N_{i}} a_{i j}\left(V_{j}^{a v e}-V_{i}^{a v e}\right)+V_{i} \\
\delta_{V_{r}}=\left(V^{r e f}-V_{i}^{a v e}\right)\left(K_{p v}+s^{-1} K_{i v}\right)
\end{gathered}
$$

where $V_{i}^{a v e}$ and $V_{j}^{\text {ave }}$ refer to the estimated bus voltages at nodes $i$ and $j$, respectively. While adjacent matrix of voltage compensation controller, the number of adjacent MGs of node (i), and measured voltage denoted $a_{i j}, N_{i}$ and $V_{i}$, respectively. Furthermore, $\delta_{V r}$ and $V^{r e f}$ represent voltage compensation and the reference voltage, respectively. Furthermore, $K_{p v}$ and $K_{i v}$ refer to the parameters of voltage controller (proportional and integral gains, respectively).

Concerning adopting distributed controllers, not only voltage deviation minimization but also the reduction in communication networks' complexity and their costs are required, and this cannot be achieved with a non-pinned distributed consensus approach. Consequently, a pinning consensus-based distributed algorithm has been presented in [15] to realize this purpose, as revealed in Section 4.2.

\subsubsection{Tertiary Control Layer}

The tertiary control layer is the third level of a hierarchy control strategy that is accountable for managing the flow of power between the MGs and an exterior power grid, which could be the grid or another MG, which can be implemented based on the secondary voltage control [87]. This level is the most complex level of the control hierarchy structure. With the advent of MG systems, the tertiary controller has emerged as a necessary tool for power and energy regulation. Even though the MG is considerably smaller than the traditional grid, the requirement for controlling the flow of power alongside energy management is critical to boost the overall efficacy of the respective system [35]. The major goal of this level is to provide optimum energy storage, energy scheduling, and power exchange management [35]. This level can be implemented in two different control strategies: the centralized approach $[7,41,64]$ and the distributed approach-with the same distributed consensus classifications in Section 3.4.2. The non-pinned distributed controller (see Figure 7) is expressed in Equations (6) and (7) as follows:

$$
S C O_{i}^{a v e}=\sum_{j \in N_{i}} b_{i j}\left(S O C_{j}^{a v e}-S O C_{i}^{a v e}\right)+S O C_{i}
$$




$$
\delta_{p f}=\left(S O C_{j}^{a v e}-S O C_{i}^{a v e}\right) \times\left(K_{p_{p}}+s^{-1} K_{i_{p}}\right)
$$

where the estimated SOCs of both batteries with their measured values are denoted by $S O C_{i}^{a v e}$ and $S O C_{i}$, respectively. Power compensation and adjacent matrix of power regulator are represented by $\delta_{P f}$ and $b_{i j}$, respectively. Both $\delta_{P f}$ and $\delta_{V r}$ are sent to the primary layer to return the DC bus voltage to its standard level and manage the power among DGs in each MG and between participant MGs. Additionally, $K_{p_{p}}$ and $K_{i_{p}}$ denote to the parameters of the power controller (proportional and integral gains, respectively).

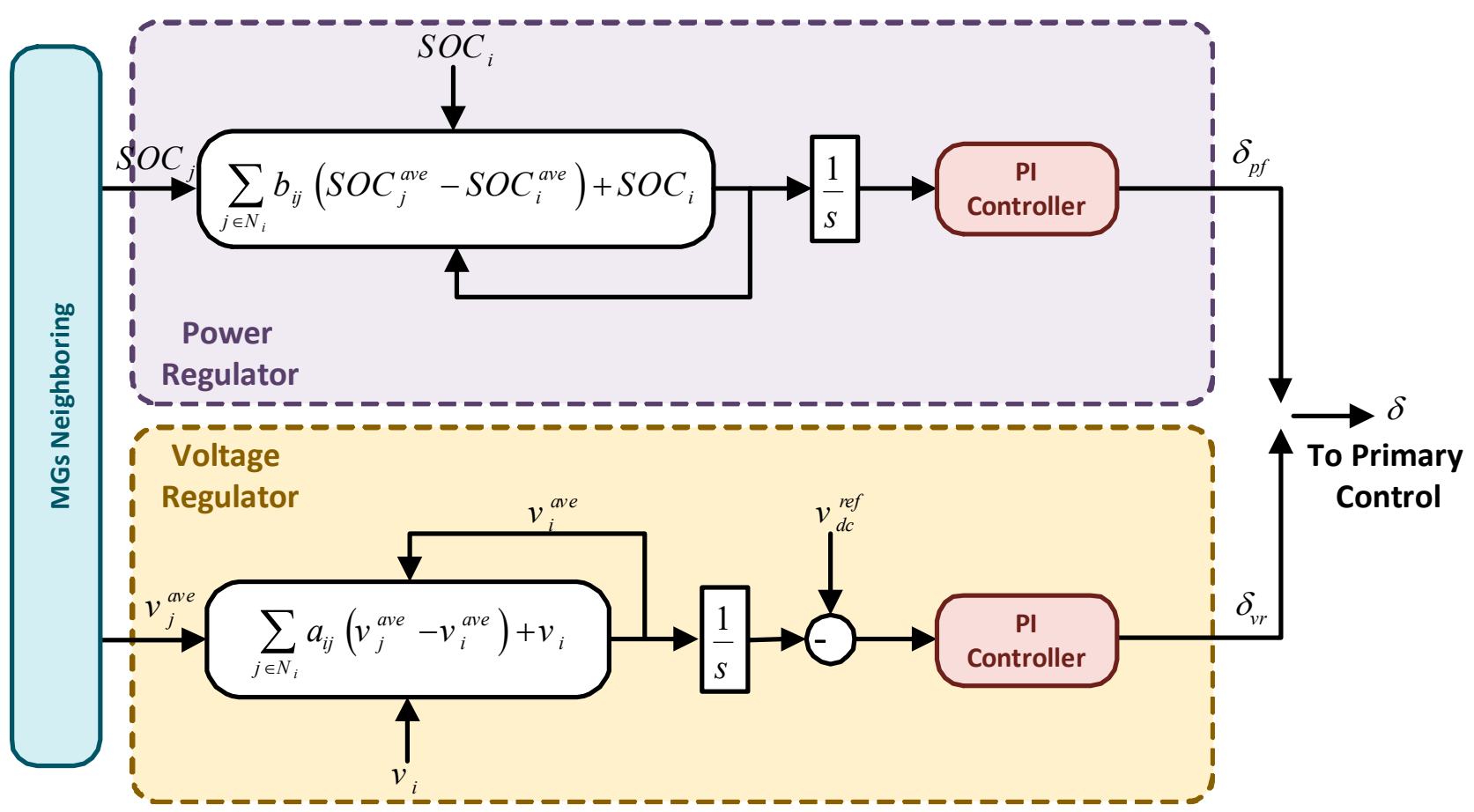

Figure 7. The non-pinned distributed consensus-based algorithm.

In summary, the hierarchical control strategy is constructed based on both centralized and decentralized control methods, and thus it combines the main advantages of these methods (centralized and decentralized). There are specific tasks to be achieved at each level to realize proper coordination of MGs inside a cluster. Concerning the type of control techniques used in each level, decentralized control is adopted in the first level. In contrast, decentralized, centralized, and distributed methods are used in the secondary level, and the third level could be achieved in either a distributed or centralized way. It is worth mentioning that distributed way used in the last two control levels is divided into nonpinning and pinning consensus protocols with three different time boundaries (infinite, finite, and fixed time boundary), which are explained in detail in Section 4. Finally, it can be easily noticed that regardless of the type of control strategies mentioned in Sections 3.1-3.4, the common objectives are to achieve a voltage adjustment and proper power exchange among MGs in a cluster, which can contribute to enhancing the performance of the cluster in providing stable and reliable power to the loads in the system under different operating conditions including load-supply uncertainty, faults, cyber-physical communication links failures, communication congestions, and communication delays. A summary of the most relevant articles is included in Table 1. 
Table 1. Presents the summary of the relevant articles with respect to control techniques of DC MGs clusters.

\begin{tabular}{|c|c|c|c|}
\hline Ref. & Objectives & Problems & Proposed Methods \\
\hline [50] & $\begin{array}{l}\text { Voltage regulation and } \\
\text { power flow control }\end{array}$ & $\begin{array}{l}\text { SOCs/Load- } \\
\text { generation } \\
\text { mismatch }\end{array}$ & $\begin{array}{l}\text { Distributed hierarchical } \\
\text { approach }\end{array}$ \\
\hline [5] & $\begin{array}{l}\text { Power exchange } \\
\text { management and no } \\
\text { circulating current }\end{array}$ & $\begin{array}{c}\text { Load-generation } \\
\text { mismatch (circulating } \\
\text { currents) }\end{array}$ & $\begin{array}{c}\text { Novel Power } \\
\text { Scheduling Mechanism }\end{array}$ \\
\hline
\end{tabular}

Method's Issues/Gaps

1. It is susceptible to communication delays.

2. Complex MGC is not considered.

3. Global SOCs balance is not realized.

4. PV generation fluctuations are not considered.

1. Outage occurrences have not been considered.

2. Machine learning techniques can be used to manage MG clusters.

3. PV power variations have not been considered.

4. Load and generation forecasting should be considered to mimic the real system in remote areas.

1. Historical/prediction data of solar irradiance need to be used to validate the effectiveness of the proposed method.

2. Uncertainty in renewable energy and actual load variations can be implemented using machine learning techniques to enhance system reliability.

3. Surplus energy can be exported to the main grid as an economic option instead of adding dummy loads if generation is more than load in all participant MGs.

1. Power quality issues and possible faults have not been investigated;

Optimal coordination of both real-time and [10] operation control, power balance among MGs, and power losses minimization

\section{Uncertainty in \\ renewable energy and \\ load variations}

The hierarchically coordinated control scheme MGs clusters are connected to the main grid.

2. Optimal parameters of PI-controllers and circulating currents minimization are not considered.

1. Nature of DGs is not considered.

2. Uncertainty of RES and load variations are not considered.

Congestion

[76] management and losses minimization
Power routing mismatching between generation and load among MGs
A novel cloud-basedapproach
3. Plug-and-Play operation is not supported.

4. High bandwidth communication is required.

1. There are still some oscillations in voltage waveforms.

2. Power flow is not controlled effectively.

3. It does not support PnP capability, which is necessary to prevent any disturbance that may occur in the system.

4. It has not been tested with real data of RESs and their uncertainties. 
Table 1. Cont

\begin{tabular}{|c|c|c|c|c|}
\hline Ref. & Objectives & Problems & Proposed Methods & Method's Issues/Gaps \\
\hline [68] & $\begin{array}{l}\text { Control of the tie-line } \\
\text { current and } \\
\text { maintaining bus } \\
\text { voltage }\end{array}$ & $\begin{array}{l}\text { High penetration in } \\
\text { renewable energy } \\
\text { resourcesMismatching } \\
\text { between the DGs and } \\
\text { ESS }\end{array}$ & $\begin{array}{c}\text { A hierarchical } \\
\text { cooperative control } \\
\text { scheme }\end{array}$ & $\begin{array}{l}\text { 1. The reference of tie-line has not } \\
\text { been achieved by using an } \\
\text { optimizing process. } \\
\text { 2. PnP ability is not supported. } \\
\text { 3. Nature of DGs is ignored. } \\
\text { 4. RES uncertainties are ignored. }\end{array}$ \\
\hline [13] & $\begin{array}{l}\text { Control the flow of } \\
\text { power and DC-link } \\
\text { voltage }\end{array}$ & $\begin{array}{l}\text { Mismatching between } \\
\text { generation and load for } \\
\text { each MG. }\end{array}$ & $\begin{array}{l}\text { A decentralized control } \\
\text { approach }\end{array}$ & $\begin{array}{l}\text { 1. This method did not tackle } \\
\text { transient stability. } \\
\text { 2. Long settling time of the voltage } \\
\text { waveform. } \\
\text { 3. SOCs of each MG did not take into } \\
\text { consideration. } \\
\text { 4. PnP operation is not supported. } \\
\text { 5. It has not been examined with } \\
\text { real-time data. }\end{array}$ \\
\hline [95] & $\begin{array}{l}\text { Proper power-sharing, } \\
\text { appropriate voltage } \\
\text { regulation, loading } \\
\text { mismatch mitigation, } \\
\text { and losses } \\
\text { minimization }\end{array}$ & $\begin{array}{l}\text { Line impedance and } \\
\text { load changes }\end{array}$ & $\begin{array}{l}\text { A fully distributed } \\
\text { fixed-time based } \\
\text { dual-layer hierarchy } \\
\text { control }\end{array}$ & $\begin{array}{l}\text { 1. Real data of RESs are not used, } \\
\text { such as historical/prediction data } \\
\text { of solar irradiance or wind speed. } \\
\text { 2. Load and RES forecasting are not } \\
\text { included. } \\
\text { 3. It is sensitive to a small state error } \\
\text { which may cause some } \\
\text { fluctuations in the system. }\end{array}$ \\
\hline [75] & $\begin{array}{l}\text { Power exchange and } \\
\text { voltage regulation }\end{array}$ & $\begin{array}{l}\text { Loading mismatch and } \\
\text { line impedance }\end{array}$ & $\begin{array}{l}\text { Distributed tertiary } \\
\text { control method }\end{array}$ & $\begin{array}{l}\text { 1. Voltage regulation has not been } \\
\text { improved properly. } \\
\text { 2. Real data of RESs are not used, } \\
\text { such as historical/prediction data } \\
\text { of solar irradiance or wind speed. } \\
\text { 3. Nature of DGs with their } \\
\text { uncertainty is ignored. } \\
\text { 4. Circulating currents are not } \\
\text { controlled. }\end{array}$ \\
\hline [79] & $\begin{array}{l}\text { Control of power flow } \\
\text { and voltage regulation }\end{array}$ & $\begin{array}{l}\text { Load-generation } \\
\text { mismatch }\end{array}$ & $\begin{array}{l}\text { PFC-hierarchical } \\
\text { control method }\end{array}$ & $\begin{array}{l}\text { 1. Real data of RESs are not used, } \\
\text { such as historical/prediction data } \\
\text { of solar irradiance or wind speed. } \\
\text { 2. High undershoot and overshoot in } \\
\text { DC-link voltage still exist. } \\
\text { 3. It has not been examined under } \\
\text { fault and PnP scenarios. }\end{array}$ \\
\hline [28] & Power flow control & RES/load variations & $\begin{array}{c}\text { The adaptive } \\
\text { distributed control } \\
\text { scheme }\end{array}$ & $\begin{array}{l}\text { 1. It may only be suitable for small } \\
\text { low voltage MGC. } \\
\text { 2. Long settling time of the voltage } \\
\text { waveform. } \\
\text { 3. Load/PV forecasting is not } \\
\text { considered. } \\
\text { 4. Stability analysis is ignored even } \\
\text { with grid-connected mode. }\end{array}$ \\
\hline
\end{tabular}


Table 1. Cont.

\begin{tabular}{|c|c|c|c|c|}
\hline Ref. & Objectives & Problems & Proposed Methods & Method's Issues/Gaps \\
\hline$[61]$ & $\begin{array}{l}\text { Proper load } \\
\text { distribution, voltage } \\
\text { stabilization, and the } \\
\text { minimization of total } \\
\text { generation }\end{array}$ & $\begin{array}{l}\text { Load and generation } \\
\text { fluctuations }\end{array}$ & $\begin{array}{c}\text { Fully distributed } \\
\text { finite-time hierarchical } \\
\text { control }\end{array}$ & $\begin{array}{l}\text { 1. Nature of DGs with their } \\
\text { uncertainty is ignored. } \\
\text { 2. Real data of RESs are not used, } \\
\text { such as historical/prediction data } \\
\text { of solar irradiance or wind speed. } \\
\text { 3. The impact of communication } \\
\text { delay on algorithm convergence is } \\
\text { not considered. } \\
\text { This strategy necessitates initial } \\
\text { conditions of the cluster that may } \\
\text { not always be available or } \\
\text { accurate. }\end{array}$ \\
\hline [42] & $\begin{array}{l}\text { SOC equalization and } \\
\text { power balancing in } \\
\text { system }\end{array}$ & $\begin{array}{l}\text { Mismatching between } \\
\text { load and supply }\end{array}$ & $\begin{array}{c}\text { SOC-featured } \\
\text { distributed tertiary } \\
\text { control }\end{array}$ & $\begin{array}{l}\text { 1. The SOC convergence and the } \\
\text { balance of output current are } \\
\text { highly sensitive to the adjustment } \\
\text { factor in the battery. } \\
\text { 2. There are still some oscillations in } \\
\text { DC-link voltage. } \\
\text { 3. Nature of DGs with their } \\
\text { uncertainty is ignored. } \\
\text { The reduction in power losses is } \\
\text { not considered in this study } \\
\text { The proposed method has not } \\
\text { been examined under fault } \\
\text { conditions and communication } \\
\text { delay. }\end{array}$ \\
\hline [15] & $\begin{array}{l}\text { Power exchange and } \\
\text { voltage regulation }\end{array}$ & $\begin{array}{c}\text { Loading mismatch } \\
\text { among neighboring } \\
\text { MGs }\end{array}$ & $\begin{array}{l}\text { Distributed tertiary } \\
\text { hierarchical control } \\
\text { strategy }\end{array}$ & $\begin{array}{l}\text { 1. Nature of DGs with their } \\
\text { uncertainty is ignored. } \\
\text { 2. Classical PI-controller with linear } \\
\text { consensus protocol is used in the } \\
\text { global and local control layers. } \\
\text { 3. It may be vulnerable to asymptotic } \\
\text { convergence. } \\
\text { 4. The power losses minimization } \\
\text { over tie-line is not considered. }\end{array}$ \\
\hline [74] & $\begin{array}{l}\text { SOCs equalization and } \\
\text { voltage regulation }\end{array}$ & $\begin{array}{l}\text { The mismatch between } \\
\text { generation and load }\end{array}$ & $\begin{array}{l}\text { Distributed control } \\
\text { framework }\end{array}$ & $\begin{array}{l}\text { 1. The system's load demand and } \\
\text { generation, storage capacity (SC), } \\
\text { and power losses should be } \\
\text { considered in SOC references } \\
\text { computation. } \\
\text { 2. Global SOCS balance is not } \\
\text { realized. } \\
\text { 3. Nature of DGs with their } \\
\text { 4. Centralized controller is required. }\end{array}$ \\
\hline [53] & $\begin{array}{l}\text { Power flow control, } \\
\text { global voltage } \\
\text { regulation, seamless } \\
\text { transition }\end{array}$ & $\begin{array}{c}\text { MGs coupling issues } \\
\text { (fault, terminal bus } \\
\text { failure) }\end{array}$ & $\begin{array}{l}\text { A novel coordinated } \\
\text { power control scheme }\end{array}$ & $\begin{array}{l}\text { 1. Complex MG cluster is not } \\
\text { considered. } \\
\text { 2. Nature of DGs with their } \\
\text { uncertainty is ignored. } \\
\text { 3. Overall system cost is increased. }\end{array}$ \\
\hline [96] & $\begin{array}{l}\text { Multidirectional power } \\
\text { flow control and fault } \\
\text { isolation }\end{array}$ & $\begin{array}{c}\text { Power } \\
\text { fluctuations /load } \\
\text { changes }\end{array}$ & $\begin{array}{c}\text { A novel modular-based } \\
\text { energy router }\end{array}$ & $\begin{array}{l}\text { 1. Nature of DGs with their } \\
\text { uncertainty is ignored. } \\
\text { 2. Classical PI-controllers are used. } \\
\text { 3. It depends on perfection in } \\
\text { choosing the power factor. } \\
\text { 4. Line impedances are ignored. }\end{array}$ \\
\hline
\end{tabular}


Table 1. Cont

\begin{tabular}{|c|c|c|c|c|}
\hline Ref. & Objectives & Problems & Proposed Methods & Method's Issues/Gaps \\
\hline [25] & $\begin{array}{l}\text { Power flow control, } \\
\text { voltage regulation, and } \\
\text { coordination of fuel } \\
\text { cell/battery power }\end{array}$ & $\begin{array}{c}\text { Uncertainty in } \\
\text { RES/LoadThe low } \\
\text { inertia of MGsTie-line } \\
\text { power losses }\end{array}$ & $\begin{array}{l}\text { MAS- coordinated } \\
\text { power control scheme }\end{array}$ & $\begin{array}{l}\text { 1. Classical PI-controllers are used. } \\
\text { 2. Real data of RESs are not used, } \\
\text { such as historical/prediction data } \\
\text { of solar irradiance or wind speed. } \\
\text { 3. Linear consensus protocol is } \\
\text { adopted. } \\
\text { 4. The cyber-physical } \\
\text { communication failure and } \\
\text { communication delays conditions } \\
\text { have not been considered. }\end{array}$ \\
\hline [64] & $\begin{array}{l}\text { Optimal power flow } \\
\text { and voltage regulation }\end{array}$ & $\begin{array}{l}\text { RES/load variations } \\
\text { and faults }\end{array}$ & $\begin{array}{c}\text { The optimized } \\
\text { hierarchical control } \\
\text { scheme }\end{array}$ & $\begin{array}{l}\text { 1. High bandwidth communication } \\
\text { is required. } \\
\text { 2. RES/load forecasting is not } \\
\text { considered. } \\
\text { 3. It is highly subjected to SPOF. } \\
\text { 4. Internal power losses in each MG } \\
\text { are not addressed. }\end{array}$ \\
\hline
\end{tabular}

\section{Consensus Protocols of the Global Control Layer}

The good performance of a cluster needs mutual coordination on the level of the global control layer amongst DC MGs inside it. From this point of view, three types of algorithms, such as particle swarm optimization (PSO), genetic algorithm (GA), and consensus algorithms, have been used in the literature to coordinate the global control layer [35]. However, the consensus algorithm is the most common one that has been ever employed because it has a better performance in comparison to its counterparts, where it allows agents to reach a quicker convergence with fewer data [34]. Consensus is one of the fundamental problems of the cooperative control of multi-agent systems. The cooperative control problem of multi-agent systems (MAS) refers to having a group of independent agents work together proficiently to accomplish collective group behavior through local interactions [97]. From this point of view, DC MGCs can be operated as a MAS to address DC voltage regulation, accurate power-sharing, and SOC balancing problems through a consensus protocol [25]. The consensus protocol can be implemented by two approaches, specifically, the centralized and distributed approaches. In the distributed approach, each MG requires us to obtain information from other MGs through a direct communication network. The communication topology amongst the MGs is typically represented as a graph, where each agent is deemed as a node, and the information exchange links are modeled as edges [21]. Detailed knowledge of graph theoretic and its lemmas is necessary for the cooperative control of MAS. Consensus protocols have been solved using a variety of techniques, including graph theory, matrix theory, and control theory [34]. The basics of graph consensus are extensively discussed in [73]; thus, they are not covered in this article.

The convergence of this algorithm can be implemented in three different boundaries, including the linear [50], finite time [80], fixed time boundaries [95]. It is worth mentioning that most works in the field of DCMMGs consider linear consensus protocol to achieve an agreement among DC MGs for the sake of simplicity [15,42,73]. Theoretically, agents attain consensus in an asymptotic convergence manner with an unlimited settling time. The asymptotic convergence controllers, on the other hand, may not be ideal for adapting the common operating conditions since MGs are susceptible to quick disruptions owing to the intermittency of DERs and speedy load fluctuations [49,98]. Further, the linear consensus algorithm used in the references mentioned above may not be compatible with the complexity of communication topology in the MMGs and the need for fast responsivity against any emergency scenario [61,80]. In addition to previous requirements mentioned in $[61,80]$, a fast convergence time and precise tracking in a short period of time are required in practical applications, which cannot be achieved in the linear consensus approach. 
To overcome these issues, a finite-time consensus algorithm has been proposed in $[61,80,89]$. The finite-time consensus approach, which may converge in a finite time or iteration number, is developed [80]. It has greater dependability to assure resilient operation of microgrid and is more appropriate with high DRG penetration. This technique allows for consensus to be established in limited steps and for all agents to reach an agreement at around the same time [99]. It is also adaptable and efficient under a variety of operating circumstances, and its convergence is ensured by thorough study. This proposed algorithm has been tested under different operational situations, including load fluctuation, outages, and PnP [89]. It also is proved to be quicker than the linear consensus technique; however, this new concept depends on initial functioning circumstances in a cluster, which may not always be accessible or even not accurate; each DG/MG needs to know the global information of the whole graph topology, which may change by adding or removing a certain unit from the system [99].

The fixed-time consensus control proposed in [81] offers a quicker convergence speed and delivers an obvious estimation of convergence time, which is irrespective of initial operating circumstances of the system, which are often unavailable in complex networks, making it a realistic method. Correspondingly, reliable multiscale consensus could be obtained by using either a fixed-time or finite-time consensus approach with external disturbances; however, both fixed-time consensus and finite-time algorithms, on the other hand, are extremely sensitive to tiny state inaccuracies, which can cause massive oscillations in the MGs cluster and impair the stability of the system. Moreover, as opposed to asymptotical control approaches, finite-time and fixed-time distributed control approaches have a quicker convergence rate but are highly vulnerable to communication delays [98]. To summarize, all types of consensus algorithms that have been mentioned above depend on classical PI-controllers in the global control levels, so they may not be able to face sudden abnormal conditions in the system. Based on the discussion, it can be concluded that consensus protocol is divided into two types, including non-pinning and pinning consensus.

\subsection{Non-Pinning Consensus Protocol}

The basic idea behind this protocol is to connect all the system's surrounding components over a communication network to exchange data. The global information may be precisely communicated in a distributed manner using the consensus protocol [50]. This approach is explained in Figure 8. Each node in the cluster is allocated an MG, and each edge on the graph depicts a communication link between two adjacent nodes. According to the concept outlined in the previous section, each node could only interact with its nearest neighbors. The graph's edges can be either unidirectional or else bidirectional. The information flow direction is represented by an edge's direction on the graph. A graph is said to be undirected if all its edges are bidirectional; it is a directed graph otherwise [15]. The Laplacian matrix, studied in [34], arises as the best technique for consensus procedures in graph theory. Most papers in the literature follow this technique, and further information may be found in $[34,35,73]$. The predicted values of voltages and states of charges in each microgrid(node) are communicated over low bandwidth communication connections, which become the foundation for convergence to a common point in these references. 


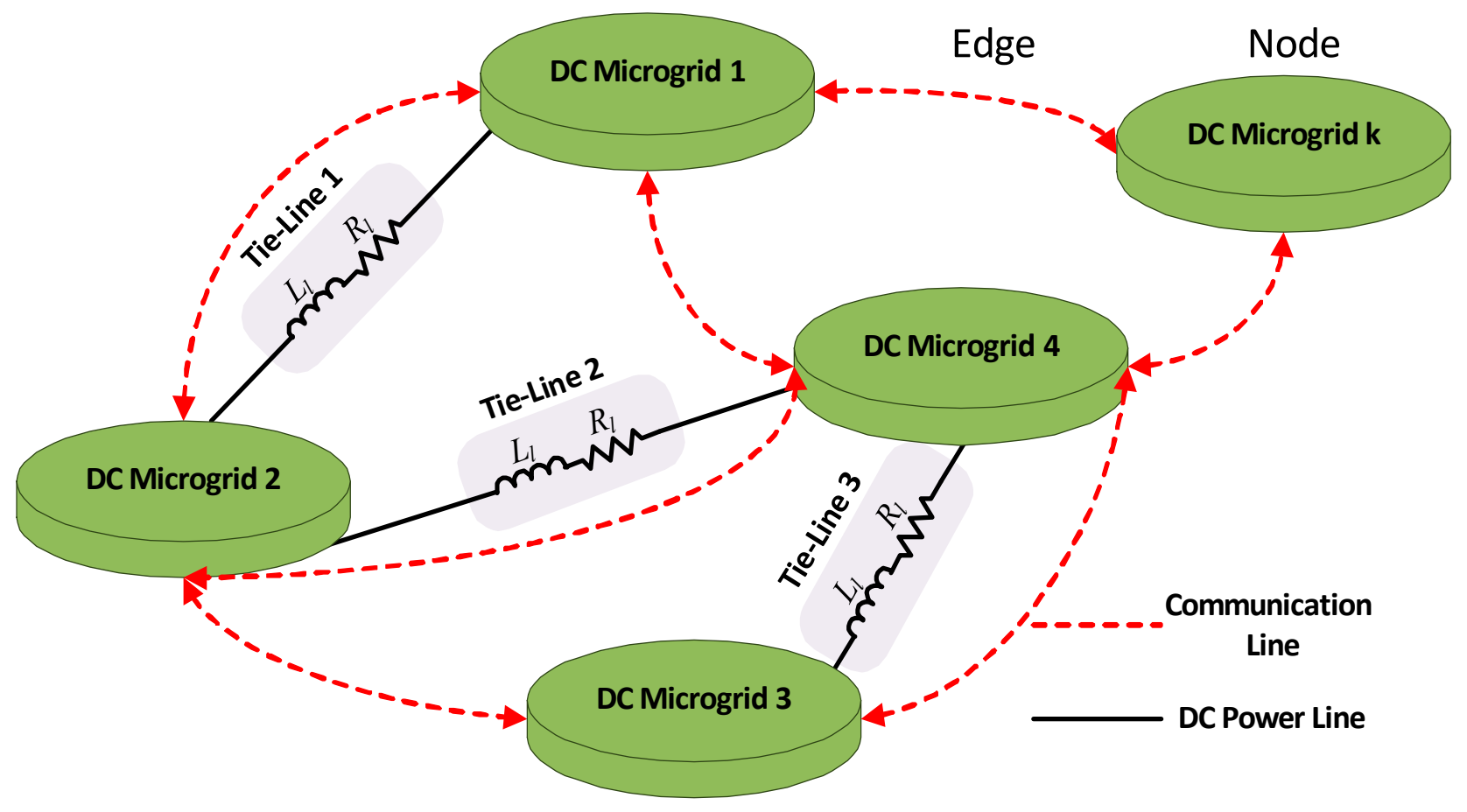

Figure 8. Non-pinning consensus protocol.

\subsection{Pinning Consensus Protocol}

The pinning approach is considered a particular type of centralization control, so instead of distributing information to all nodes in the network, the pinning approach pins just a small number of nodes to disseminate it across the other nodes in the network. This approach lowers the cost of transmission while also increasing the system's dependability. Nodes are typically divided into two categories: pinning nodes and pinned nodes [8]. In the field of MGs, because only a tiny proportion of the DGs must be controlled by uncomplex feedback controllers, the pinning-based approach is particularly well suited to large-scale MGs with a high number of DGs. To minimize the number of DG controllers, in turn, to lower the communication and control costs, it is logical to adopt this technique [100]. To comprehend this process, the pinning-based concept is shown in Figure 9, where pinned DGs are a subset of DGs in each MG that have immediate access to data shared with nearby MGs. Other DGs in an individual MG will follow pinned DGs [60]. As a result, communications costs of the cluster are considerably decreased, as communications are limited to participant MGs in proximity places [15]. By adopting this approach, two layers are used to coordinate MGs in the cluster, including a local control layer that is accountable for voltage adjustment alongside proportional power-sharing amongst DGs in MG, while the global control layer is employed to realize accurate power exchange amongst MGs in a cluster with proper global voltage regulation.

This approach has been used in many articles in the literature because of the abovementioned features. For example, a fully distributed control approach with local and global layers is suggested in [87] to ensure appropriate power-sharing for DC clustered MGs with various DG types. To avoid the complexity of central controllers, each DG can intercommunicate exclusively with its two neighbors over a two-layer communication system. The suggested approach may improve DC MG control's robustness in the face of the failure of communications links, and low-bandwidth communication can be employed for data exchange. It also has PnP functionality as well as flexibility. It may, however, be subject to communications delays, so high vacillations and low convergence rates occur in the system. In [8], a distributed control technique based on a pinning method is presented to adjust the power flow of tie-line between two coupled and owned independent DC MGs clusters. In comparison to the centralization technique, this strategy improves system dependability 
and lowers implementation costs while also enhancing DC bus voltage stabilization and lowering the total generating cost of DC clustered microgrids. Although fault resilience and PnP operation are assured, the article does not accomplish power loss reduction across tie-line and does not tackle oscillations in the cluster because of communication delays. Moreover, even though the design of clustered MGs is multi-bus architecture, including a diverse mix of energy resources, the methodology is not tested with a complicated DC MG cluster to demonstrate its superiority over existing techniques.

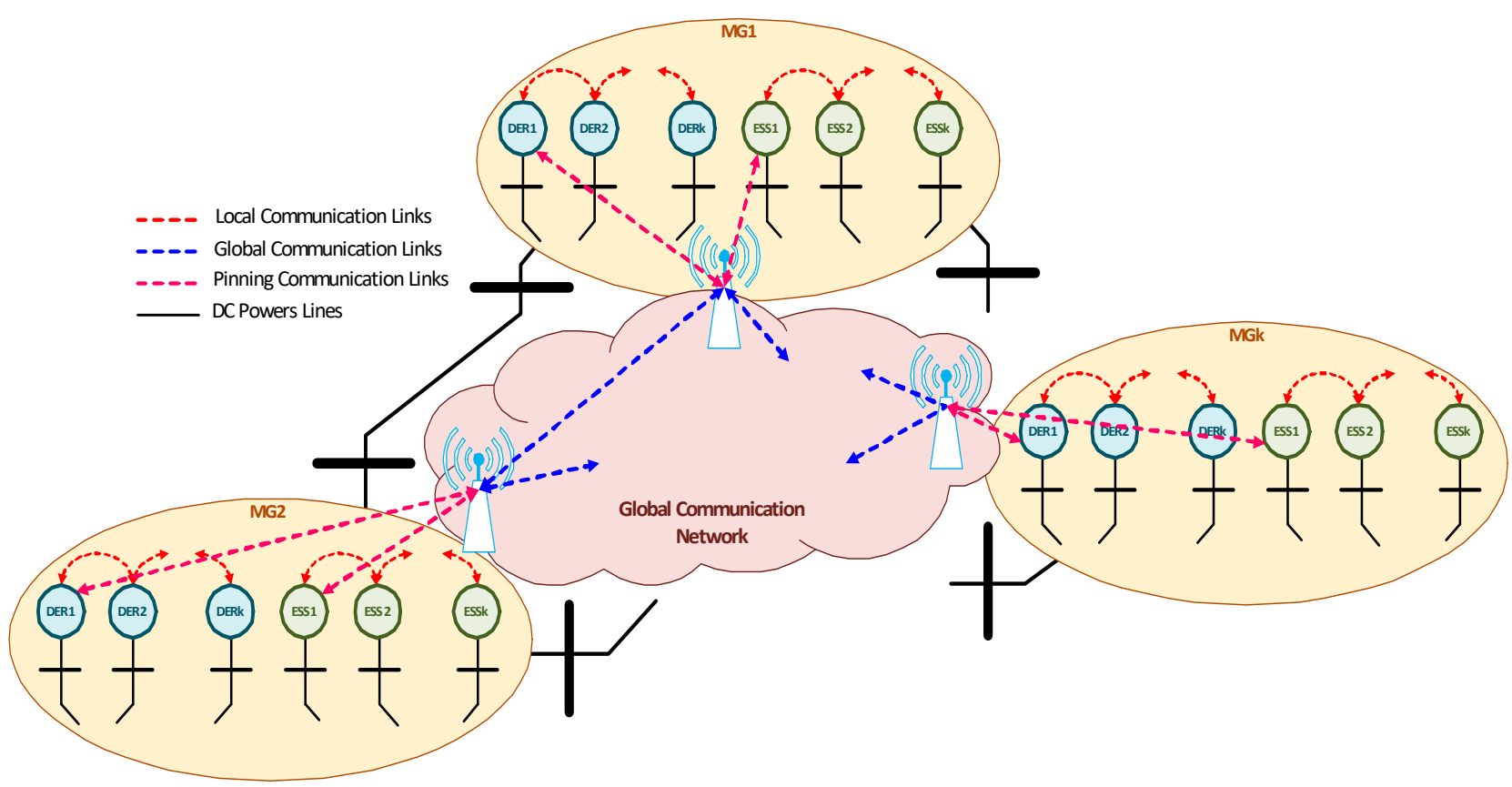

Figure 9. Pinning consensus protocol.

It can be noticed that the protocols in $[8,87]$ are continuous, which is incompatible with real-world applications. To resolve this inconsistency, a discrete-time control approach is necessary [77]. The intermittent communication methods are featured by less communication pressure while also helping the system converge quicker. In this respect, a novel two-layer discrete-time iterative cooperation (TDIC) approach for the DC MG cluster using a two-layer cyber network method is proposed in [88]. The proposed technique enables all pinning-DGs' current outputs alongside estimated voltages to match their pinned-DGs, allowing all DGs' weighted average voltages to be controlled to an adequate limit and precise current-sharing inside individual MG and across the cluster to be achieved at the same time. By adopting this method, the communication burden is decreased, and the convergence speed is increased; however, this article does not consider the minimization of power losses and robustness against cyber-physical communication failures. A fully distributed control system dependent on a pinning technique is proposed in [60] with a finite-time manner in [80] to coordinate MGs in the cluster by utilizing a two-layer sparse communications infrastructure. The average voltage of MG is regulated to sustain the balance of generation-demand power in the local control layer, while power-sharing among microgrids is optimally managed to lessen the total generation cost (TGC) of DC clustered MGs. It found that the presented method is robust against load changes, PnP's capability, and communication failures; however, the convergence time of this method relies on the initial operation status of the cluster, which may not be precise or sometimes unavailable, and also the units in [60] reach consensus in an asymptotical convergence manner; thereby, it is not suitable to be applied in the large MGs cluster. Further, this article has not considered load and energy fluctuations simultaneously and fault detection inside MG and MG clusters. 
From the previous discussions, it was found that all the references mentioned above, excluding [80], are conducted based on a linear consensus-based algorithm, which may not be suitable for microgrids cluster as discussed earlier. With a view to addressing the issues in the preceding references, a distributed fixed-time-based dual-layer secondary controller is presented [81,95] to keep MG cluster coordination at both the global and local levels within a defined settling time. It can be shown that global loading imbalance mitigation, proportional sharing of load current, and voltage regulation are achieved for each MG. The fixed time distributed control approach is featured by its robustness against unpredictable disruptions, so the MGs cluster adaptability to changing system circumstances such as converter plug out as well as cyber complexities, including variable communication latency and data packet losses, is realized. The common advantage associated with references $[81,95]$ is the reduced communication protocol that may be used more efficiently than finite-time distributed control techniques; however, the authors in $[91,95]$ ignore reducing the power losses of the tie-line.

To sum up, it can be noticed that fewer computational burdens compared to previous methods and reliability is realized by adopting a pinning concept [8]; however, most references ignore the heterogeneity of energy sources and uncertainties in generation and load as well as real data have not been considered. Furthermore, there is a lack of focus on adopting this approach in the DC MG cluster. Due to the importunacy of this concept and to increase interest in it, the most relevant articles are summarized in Table 2, where we present some vital aspects that require to be addressed in future research.

Table 2. Summary of relevant articles that adopt the pinning-based approach.

\begin{tabular}{|c|c|c|c|c|}
\hline Ref & Method & Objectives & Merits & Demerits \\
\hline \multirow{4}{*}{ [78] } & \multirow{4}{*}{$\begin{array}{l}\text { A distributed } \\
\text { hierarchical control } \\
\text { strategy }\end{array}$} & \multirow{4}{*}{$\begin{array}{l}\text { Current sharing and } \\
\text { voltage regulation }\end{array}$} & $\begin{array}{l}\text { 1. Less computational } \\
\text { burdens. }\end{array}$ & $\begin{array}{l}\text { 1. Natures of DGs have not been } \\
\text { considered. }\end{array}$ \\
\hline & & & $\begin{array}{l}\text { 2. Both current sharing } \\
\text { alongside DC voltage } \\
\text { regulation is partially } \\
\text { realized. }\end{array}$ & $\begin{array}{l}\text { 2. Uncertainties in Load and RES are } \\
\text { ignored. }\end{array}$ \\
\hline & & & 3. PnP operation is obtained. & $\begin{array}{l}\text { 3. Minimization of internal power losses } \\
\text { is disregarded. }\end{array}$ \\
\hline & & & & $\begin{array}{l}\text { 4. Because of PI-controller settings, there } \\
\text { is still a conflict between voltage } \\
\text { adjustment and current distribution. }\end{array}$ \\
\hline \multirow{7}{*}{ [27] } & \multirow{7}{*}{$\begin{array}{l}\text { A fully distributed } \\
\text { consensus-based } \\
\text { control scheme }\end{array}$} & \multirow{7}{*}{$\begin{array}{l}\text { Optimal power-sharing, } \\
\text { voltage regulation, and } \\
\text { generation costs }\end{array}$} & $\begin{array}{l}\text { 1. The optimum power } \\
\text { dispatch is obtained. }\end{array}$ & $\begin{array}{l}\text { 1. It is more susceptible to communication } \\
\text { reliability problems, including packet loss } \\
\text { and communication delays. }\end{array}$ \\
\hline & & & $\begin{array}{l}\text { 2. DC bus voltage. regulation } \\
\text { is improved. }\end{array}$ & $\begin{array}{l}\text { 2. Infinite-time convergence is adopted, so } \\
\text { it may not be able to face the fast and } \\
\text { sudden disturbances caused by RES and } \\
\text { load variations. }\end{array}$ \\
\hline & & & $\begin{array}{l}\text { 3. It is resilient to the failure } \\
\text { of a single link. }\end{array}$ & $\begin{array}{l}\text { 3. Uncertainties in Load and RES are } \\
\text { ignored. }\end{array}$ \\
\hline & & & $\begin{array}{l}\text { 4. It is featured by robustness } \\
\text { against physical failures. }\end{array}$ & 4. Classical PI controllers are used. \\
\hline & & & & $\begin{array}{l}\text { 5. Natures of DGs have not been } \\
\text { considered. }\end{array}$ \\
\hline & & & & $\begin{array}{l}\text { 6. Extra costs are added because of using } \\
\text { interlinking converters. }\end{array}$ \\
\hline & & & & $\begin{array}{l}\text { 7. Minimization of power losses is not } \\
\text { included. }\end{array}$ \\
\hline
\end{tabular}


Table 2. Cont.

\begin{tabular}{|c|c|c|c|c|}
\hline Ref & Method & Objectives & Merits & Demerits \\
\hline \multirow{5}{*}{ [95] } & \multirow{5}{*}{$\begin{array}{l}\text { A fully distributed } \\
\text { fixed-time based } \\
\text { dual-layer } \\
\text { hierarchy control }\end{array}$} & $\begin{array}{l}\text { Power-exchange and } \\
\text { voltage adjustment }\end{array}$ & $\begin{array}{l}\text { 1. Power exchange and } \\
\text { voltage adjustment are } \\
\text { achieved. }\end{array}$ & $\begin{array}{l}\text { 1. Uncertainties in Load and RES are } \\
\text { ignored. }\end{array}$ \\
\hline & & $\begin{array}{l}\text { loading mismatch } \\
\text { mitigation and losses } \\
\text { minimization. }\end{array}$ & $\begin{array}{l}\text { 2. Loading mismatch and } \\
\text { power losses are decreased. }\end{array}$ & $\begin{array}{l}\text { 2. The issues of communication delays } \\
\text { exist. }\end{array}$ \\
\hline & & & & $\begin{array}{l}\text { 3. Real data of RESs are not used, such as } \\
\text { historical/prediction data of solar } \\
\text { irradiance or wind speed. }\end{array}$ \\
\hline & & & & $\begin{array}{l}\text { 4. Load and RES forecasting are not } \\
\text { included. }\end{array}$ \\
\hline & & & & $\begin{array}{l}\text { 5. It is sensitive to slight inaccuracy in the } \\
\text { system. }\end{array}$ \\
\hline \multirow{4}{*}{ [80] } & \multirow{4}{*}{$\begin{array}{l}\text { A fully distributed } \\
\text { finite-time based } \\
\text { dual layer hierarchy } \\
\text { control }\end{array}$} & \multirow{4}{*}{$\begin{array}{l}\text { Economic power } \\
\text { sharing and voltage } \\
\text { regulation }\end{array}$} & $\begin{array}{l}\text { 1. Optimal power exchange } \\
\text { alongside DC bus voltage } \\
\text { adjustment are controlled } \\
\text { within a limited-time } \\
\text { domain. }\end{array}$ & $\begin{array}{l}\text { 1. It is susceptible to communication } \\
\text { delays. }\end{array}$ \\
\hline & & & $\begin{array}{l}\text { 2. It is featured by resiliency } \\
\text { against failures on the virtual } \\
\text { communication network. }\end{array}$ & $\begin{array}{l}\text { 2. Incremental costs and TGC is increased } \\
\text { during PnP operation. }\end{array}$ \\
\hline & & & $\begin{array}{l}\text { 3. It has a more robust } \\
\text { functioning with a faster } \\
\text { convergence time and better } \\
\text { dynamism, making it more } \\
\text { suited to multi-MGs with } \\
\text { rapid intermittent DRGs. }\end{array}$ & $\begin{array}{l}\text { 3. Load and RES uncertainties are } \\
\text { ignored. }\end{array}$ \\
\hline & & & $\begin{array}{l}\text { 4. PnP capability is } \\
\text { supported. }\end{array}$ & $\begin{array}{l}\text { 4. Natures of DGs have not been } \\
\text { considered. }\end{array}$ \\
\hline \multirow{5}{*}{ [87] } & \multirow{5}{*}{$\begin{array}{l}\text { A distributed } \\
\text { two-layer control } \\
\text { approach }\end{array}$} & \multirow{5}{*}{$\begin{array}{l}\text { Economic power } \\
\text { sharing and voltage } \\
\text { adjustment }\end{array}$} & $\begin{array}{l}\text { 1. DGs' generation cost is } \\
\text { reduced. }\end{array}$ & 1. It is sensitive to communication delays. \\
\hline & & & $\begin{array}{l}\text { 2. The global power balance } \\
\text { is achieved. }\end{array}$ & $\begin{array}{l}\text { 2. Incremental costs and TGC is increased } \\
\text { during the PnP process. }\end{array}$ \\
\hline & & & 3. It has PnP capability. & $\begin{array}{l}\text { 3. Uncertainties in load and RES are } \\
\text { ignored. }\end{array}$ \\
\hline & & & $\begin{array}{l}\text { 4. It is featured by robustness } \\
\text { against cyber communication } \\
\text { failures and latency. }\end{array}$ & $\begin{array}{l}\text { 4. Natures of DGs have not been } \\
\text { considered. }\end{array}$ \\
\hline & & & $\begin{array}{l}\text { 5. Pinning-based control } \\
\text { approach is adopted to } \\
\text { reduce communication links } \\
\text { and lessen control costs. }\end{array}$ & 5. Linear consensus protocol is employed. \\
\hline \multirow{3}{*}{ [60] } & \multirow{3}{*}{$\begin{array}{l}\text { A distributed } \\
\text { two-layer control } \\
\text { approach }\end{array}$} & \multirow{3}{*}{$\begin{array}{l}\text { DC bus voltage } \\
\text { adjustment and } \\
\text { optimum load sharing }\end{array}$} & $\begin{array}{l}\text { 1. A simpler communication } \\
\text { network is required. }\end{array}$ & $\begin{array}{l}\text { 1. It may be vulnerable to communication } \\
\text { delays. }\end{array}$ \\
\hline & & & $\begin{array}{l}\text { 2. It is featured by the } \\
\text { resiliency against both } \\
\text { physical and losses. }\end{array}$ & 2. Computational burdens still exist. \\
\hline & & & $\begin{array}{l}\text { 3. Total generation costs are } \\
\text { reduced. }\end{array}$ & $\begin{array}{l}\text { 3. The convergence rate may not be } \\
\text { ensured. }\end{array}$ \\
\hline
\end{tabular}


Table 2. Cont.

\begin{tabular}{|c|c|c|c|c|}
\hline Ref & Method & Objectives & Merits & Demerits \\
\hline & & & $\begin{array}{l}\text { 4. Voltage regulation and } \\
\text { optimal load sharing are } \\
\text { achieved. }\end{array}$ & $\begin{array}{l}\text { 4. Uncertainties in load and RES are } \\
\text { ignored. }\end{array}$ \\
\hline & & & & $\begin{array}{l}\text { 5. Natures of DGs have not been } \\
\text { considered. }\end{array}$ \\
\hline \multirow{4}{*}{ [88] } & \multirow{4}{*}{$\begin{array}{c}\text { A two-layer } \\
\text { discrete-time } \\
\text { iterative } \\
\text { cooperative (TDIC) } \\
\text { scheme }\end{array}$} & \multirow{4}{*}{$\begin{array}{l}\text { Voltage regulation and } \\
\text { current sharing }\end{array}$} & $\begin{array}{l}\text { 1. Communication pressure } \\
\text { reduction and faster } \\
\text { convergence speed are } \\
\text { realized. }\end{array}$ & $\begin{array}{l}\text { 1. Uncertainties in RES and load demand } \\
\text { are ignored. }\end{array}$ \\
\hline & & & $\begin{array}{l}\text { 2. Accurate current sharing } \\
\text { and regulated voltage are } \\
\text { achieved. }\end{array}$ & $\begin{array}{l}\text { 2. Natures of DGs have not been } \\
\text { considered. }\end{array}$ \\
\hline & & & & 3. Classical PI controllers are adopted. \\
\hline & & & & $\begin{array}{l}\text { 4. Power losses reduction has not been } \\
\text { considered. }\end{array}$ \\
\hline
\end{tabular}

\section{Findings and Discussions}

The core objective of this section is to summarize the key points that have been noticed in the previous articles regarding the coordination of DC MGs clusters. It is found that there are different aspects required to be deemed in the DC MG cluster, including power exchange among the participant MGs and voltage regulation of DC-link, which needs to be regulated efficiently to achieve good coordination of all MGs in a cluster under various operating conditions, including load changes, RES variations, and outages and this is the main purpose of using different control strategies in the literature. From the tables mentioned above, it can be noticed most of the articles are characterized by the following: Most of the articles ignored the nature of DGs and their uncertainty, which is considered important when trying to mimic the behavior of a real power grid.

(i) The centralized control strategy is the least considered technique in recent years.

(ii) Real-time data of both load demand and RES have not been considered to validate the proposed control methods.

(iii) There is no emphasis on load forecasting, which is vital to be considered, although load demand is varied over time.

(iv) Classical PI controllers are dominant in all control levels, which may not always be able to face uncertainties or unpredictable conditions.

(v) Communication networks are required to transfer data, whether to the central controller or among neighboring MGs. Hence, the effect of the communication delays on the cluster's performance is noticeable in some articles.

(vi) Linear consensus protocol-based point is usually used in coordinating MG in a cluster, so it may not be able to experience the abrupt fluctuations in load demand and generated power; however, the fixed-time and finite time consensus approaches have been considered in recent years to overcome the defects of the infinite time consensus method.

(vii) Although the importunacy of the pinning approach in simplifying communication networks and accordingly cost reduction, it has not been adopted on a large scale in microgrid clusters.

(viii) It can be easily noticed that a fixed-time consensus distributed hierarchy control strategy based on a pinning-based approach can be chosen as the best option to be adopted in coordinating DC MGs in a cluster.

Based on the drawbacks mentioned above, several recommendations are proposed as follows: 
A. Forecasting renewable energy sources and load is considered an essential factor that needs to be included in future research because of its importunacy in improving system reliability. From the literature, it is noticed that there is no holistic model that can forecast the amount of solar radiation, temperature, wind speed, load demand, and SOCs of the batteries simultaneously; however, only one article presents a model that includes MGs mentioned parameters by using hybrid machine learning algorithms [101]; therefore, a new model that includes parameters in [101] and SOCs of the batteries can be forecasted by means of hybrid machine learning algorithms that need to be considered in future research.

B. Machine learning can be used as a decision-maker instead of a consensus. By adopting this new technique, the system can be able to predict any disturbance that may occur because of uncertainty in the load and renewable energy sources and other disturbances.

C. PSO, GA, and consensus algorithms are the main algorithms that have been used in the literature to coordinate the global control layer in microgrids. Hybridization among them would be a better choice to be adopted in future research.

D. Classical PI controllers are dominant in the literature as the main controller for both local and global control layers. These controllers can be replaced by new controllers such as non-linear, predictive, super-twisting sliding mode controllers (STMC); thereby, the system will be able to resist any abnormal operating conditions that may occur because of uncontrollable loads and the intermittency of renewable energy sources.

E. A classical tuning method is usually used in the literature to determine controllers' parameters; however, meta-heuristic algorithms are preferable options to be used to optimize the parameters of classical and advanced controllers.

F. Repetitive, predictive controllers, STMC, and artificial neural networks can be used in the local control layer (LCL) to enhance the performance of droop and adaptive control techniques. Moreover, metaheuristics algorithms can play a vital role in improving the LCL performance.

G. PnP operation is a highly significant feature that needs to be focused on to realize the stable operation of the MGs cluster by isolating faulty parts in case of any abnormal conditions may occur. Still, it is found that there is not much focus on the topic in the DC MG clusters.

H. Communication delays are one of the issues that negatively impact the performance of the MGs cluster. Some communication protocols, including UWB and WIFI, have been proposed in [15] that can be used to overcome this issue.

I. A bypass coupler can be used in the DC MGs cluster to boost its reliability in case of any fault in the main feeder that provides power to a specific MG in a cluster.

J. Based on item I in the main findings, a holistic model can be designed by adopting the best control technique in item $\mathrm{I}$, including items $\mathrm{A}, \mathrm{D}$, and $\mathrm{E}$ from recommendations points.

\section{Conclusions}

In this paper, MGC connections and control strategies have been reviewed with a detailed analysis to comprehend the up-to-date direction in the field of DC MG clusters. MMGs connection methods, including direct and indirect connection ways, are included with the merits and demerits of each one; therefore, different factors such as costs, voltage inequality, number of losses, and fault isolation should be considered in the case of selecting a specific type of connection to interconnect MGs in a cluster. Classification of control strategies, including centralized, decentralized, distributed, and hierarchal control strategies with associated advantages and limitations of each method, are reviewed thoroughly. The purpose of our study is to provide researchers with a clear picture of the best control method that should be chosen to implement their project. 
Author Contributions: Conceptualization, methodology, writing —original draft preparation, Z.H.A.A.T.; writing-review and editing, supervision, investigation, and visualization, T.T.L., G.F. and F.B. All authors have read and agreed to the published version of the manuscript.

Funding: This research received no external funding.

Institutional Review Board Statement: Not applicable.

Informed Consent Statement: Not applicable.

Data Availability Statement: Not applicable.

Acknowledgments: The authors would like to acknowledge Al-Furat Al-Awsat Technical University and MBIE SSIF AETP project entitled 'Architecture of the Future Low-Carbon, Resilient, Electrical Power System' for the financial support and in-kind support, respectively.

Conflicts of Interest: The authors declare no conflict of interest.

\section{References}

1. Kumaravel, S.; Ashok, S. Adapted multilayer feedforward ANN based power management control of solar photovoltaic and wind integrated power system. In Proceedings of the ISGT2011-India, Kollam, India, 1-3 December 2011. [CrossRef]

2. Iqbal, S.; Khan, H.A.; Nasir, M.; Guerrero, J.M. Efficient Resource Sizing and Placement for Clustered Solar DC Microgrids. In Proceedings of the IEEE Power Engineering Society Transmission and Distribution Conference, Chicago, IL, USA, 12-15 October 2020. [CrossRef]

3. Kollimalla, S.K.; Mishra, M.K.; Narasamma, N.L. Design and analysis of novel control strategy for battery and supercapacitor storage system. IEEE Trans. Sustain. Energy 2014, 5, 1137-1144. [CrossRef]

4. Han, Y.; Ning, X.; Yang, P.; Xu, L. Review of Power Sharing, Voltage Restoration and Stabilization Techniques in Hierarchical Controlled DC Microgrids. IEEE Access 2019, 7, 149202-149223. [CrossRef]

5. Wahid, A.; Iqbal, J.; Qamar, A.; Ahmed, S.; Basit, A.; Ali, H.; Aldossary, O.M. A novel power scheduling mechanism for islanded DC microgrid cluster. Sustainability 2020, 12, 6918. [CrossRef]

6. Gao, F.; Kang, R.; Cao, J.; Yang, T. Primary and secondary control in DC microgrids: A review. J. Mod. Power Syst. Clean Energy 2019, 7, 227-242. [CrossRef]

7. Tah, A.; Das, D. An Enhanced Droop Control Method for Accurate Load Sharing and Voltage Improvement of Isolated and Interconnected DC Microgrids. IEEE Trans. Sustain. Energy 2016, 7, 1194-1204. [CrossRef]

8. Mudaliyar, S.; Duggal, B.; Mishra, S. Distributed Tie-Line Power Flow Control of Autonomous DC Microgrid Clusters. IEEE Trans. Power Electron. 2020, 35, 11250-11266. [CrossRef]

9. Sathishkumar, R.; Kollimalla, S.K.; Mishra, M.K. Dynamic energy management of micro grids using battery super capacitor combined storage. In Proceedings of the 2012 Annual IEEE India Conference (INDICON), Kochi, India, 7-9 December 2012. [CrossRef]

10. Xu, Q.; Xu, Y.; Xu, Z.; Xie, L.; Blaabjerg, F. A Hierarchically Coordinated Operation and Control Scheme for DC Microgrid Clusters under Uncertainty. IEEE Trans. Sustain. Energy 2021, 12, 273-283. [CrossRef]

11. Lasseter, R.H. MicroGrids. In Proceedings of the 2002 IEEE Power Engineering Society Winter Meeting. Conference Proceedings (Cat. No.02CH37309), New York, NY, USA, 27-31 January 2002; Volume 1, pp. 305-308. [CrossRef]

12. Yang, J.; Jin, X.; Wu, X.; Acuna, P.; Aguilera, R.P.; Morstyn, T.; Agelidis, V.G. Decentralised control method for DC microgrids with improved current sharing accuracy. IET Gener. Transm. Distrib. 2017, 11, 696-706. [CrossRef]

13. Adhikari, S.; Xu, Q.; Tang, Y.; Wang, P. Decentralized control of DC microgrid clusters. In Proceedings of the 2017 IEEE 3rd International Future Energy Electronics Conference and ECCE Asia, Kaohsiung, Taiwan, 3-7 June 2017. [CrossRef]

14. Ghorbal, M.J.B.; Moussa, S.; Ziani, J.A.; Slama-Belkhodja, I. A comparison study of two DC microgrid controls for a fast and stable DC bus voltage. Math. Comput. Simul. 2021, 184, 210-224. [CrossRef]

15. Moayedi, S.; Davoudi, A. Distributed Tertiary Control of DC Microgrid Clusters. IEEE Trans. Power Electron. 2016, 31, 1717-1733. [CrossRef]

16. Al-Ismail, F.S. DC Microgrid Planning, Operation, and Control: A Comprehensive Review. IEEE Access 2021, 9, 36154-36172. [CrossRef]

17. Peyghami, S.; Mokhtari, H.; Blaabjerg, F. Hierarchical Power Sharing Control in DC Microgrids. In Microgrid: Advanced Control Methods and Renewable Energy System Integration; Butterworth-Heinemann: Oxford, UK, 2017. [CrossRef]

18. Elhassaneen, H.A.E.; Tsuji, T. Cooperative Decentralized Tertiary Based Control of DC Microgrid with Renewable Distributed Generation. In Proceedings of the 2019 IEEE Third International Conference on DC Microgrids (ICDCM), Matsue, Japan, 20-23 May 2019. [CrossRef]

19. Aboelsoud, H.; Tsuji, T. Cooperative decentralized hierarchical based voltage control of DC microgrids. In Proceedings of the 2019 29th Australasian Universities Power Engineering Conference (AUPEC), Nadi, Fiji, 26-29 November 2019. [CrossRef] 
20. Saleh, M.S.; Althaibani, A.; Esa, Y.; Mhandi, Y.; Mohamed, A.A. Impact of clustering microgrids on their stability and resilience during blackouts. In Proceedings of the 2015 International Conference on Smart Grid and Clean Energy Technologies (ICSGCE), Offenburg, Germany, 20-23 October 2015. [CrossRef]

21. Shafiee, Q.; Dragicevic, T.; Vasquez, J.C.; Guerrero, J.M. Hierarchical control for multiple DC-microgrids clusters. In Proceedings of the 2014 IEEE 11th International Multi-Conference on Systems, Signals \& Devices (SSD14), Barcelona, Spain, 11-14 February 2014; pp. 1-6. [CrossRef]

22. Uhlemeyer, B.; Jakob, J.; Zdrallek, M.; Baumann, C.; Wellßow, W.; Dickert, J.; Rasti, S.J.; Blumberg, G.; Schinke-Nendza, A. Cellular Approach as a Principle in Integrated Energy System Planning and Operation. In Proceedings of the CIRED Workshop, Online Conference, 22-23 September 2020. [CrossRef]

23. Hoth, K.; Steffen, T.; Wiegel, B.; Youssfi, A.; Babazadeh, D.; Venzke, M.; Becker, C.; Fischer, K.; Turau, V. Holistic Simulation Approach for Optimal Operation of Smart Integrated Energy Systems under Consideration of Resilience, Economics and Sustainability. Infrastructures 2021, 6, 150. [CrossRef]

24. Thier, P.; Giese, B.; Brand, U.; Schnuelle, C.; Petschow, U.; Heinbach, K.; Goessling-Reisemann, S.; von Gleich, A. Investigating the opportunities to implement a 'cellular approach' in two regional energy systems in Germany from a socio-technical point of view. In Proceedings of the International ETG Congress, Bonn, Germany, 28-29 November 2017.

25. Han, Y.; Pu, Y.; Li, Q.; Fu, W.; Chen, W.; You, Z.; Liu, H. Coordinated power control with virtual inertia for fuel cell-based DC microgrids cluster. Int. J. Hydrogen. Energy 2019, 44, 25207-25220. [CrossRef]

26. Guo, L.; Li, P.; Li, X.; Huang, D.; Zhu, J. Flexible control of DC interlinked multiple MGs cluster. IET Gener. Transm. Distrib. 2019, 13, 2088-2101. [CrossRef]

27. Fan, Z.; Fan, B.; Peng, J.; Liu, W. Distributed Hierarchical Control for Optimal Power Dispatch in Multiple DC Microgrids. IEEE Syst. J. 2020, 14, 1-11. [CrossRef]

28. Ciornei, I.; Albu, M.; Sănduleac, M.; Rodriguez-Diaz, E.; Teodorescu, R.; Guerrero, J. Adaptive Distributed EMS for Small Clusters of Resilient LVDC Microgrids. In Proceedings of the 2018 IEEE International Conference on Environment and Electrical Engineering and 2018 IEEE Industrial and Commercial Power Systems Europe (EEEIC/I\&CPS Europe), Palermo, Italy, 12-15 June 2018. [CrossRef]

29. Lai, J.; Lu, X.; Yu, X.; Yao, W.; Wen, J.; Cheng, S. Distributed multi-DER cooperative control for master-slave-organized microgrid networks with limited communication bandwidth. IEEE Trans. Ind. Inform. 2019, 15, 3443-3456. [CrossRef]

30. Tsikalakis, A.G.; Hatziargyriou, N.D. Centralized control for optimizing microgrids operation. In Proceedings of the IEEE Transactions on Energy Conversion, Detroit, MI, USA, 24-28 July 2011; Volume 23. [CrossRef]

31. Babazadeh-Dizaji, R.; Hamzeh, M.; Hekmati, A. Power Sharing in Multiple DC Microgrids Based on Concentrated Control. In Proceedings of the Electrical Engineering (ICEE), Iranian Conference, Mashhad, Iran, 8-10 May 2018. [CrossRef]

32. Kumar, M.; Srivastava, S.C.; Singh, S.N.; Ramamoorty, M. Development of a control strategy for interconnection of islanded direct current microgrids. IET Renew. Power Gener. 2015, 9, 284-296. [CrossRef]

33. Meng, L.; Shafiee, Q.; Trecate, G.F.; Karimi, H.; Fulwani, D.; Lu, X.; Guerrero, J.M. Review on Control of DC Microgrids and Multiple Microgrid Clusters. IEEE J. Emerg. Sel. Top. Power Electron. 2017, 5, 928-948. [CrossRef]

34. Abhishek, A.; Devassy, S.; Akbar, S.A.; Singh, B. Consensus Algorithm based Two-Level Control Design for a DC Microgrid. In Proceedings of the 2020 IEEE International Conference on Power Electronics, Smart Grid and Renewable Energy (PESGRE2020), Cochin, India, 2-4 January 2020. [CrossRef]

35. Abhishek, A.; Ranjan, A.; Devassy, S.; Verma, B.K.; Ram, S.K.; Dhakar, A.K. Review of hierarchical control strategies for DC microgrid. IET Renew. Power Gener. 2020, 14, 1631-1640. [CrossRef]

36. Shuai, Z.; Fang, J.; Ning, F.; Shen, Z.J. Hierarchical structure and bus voltage control of DC microgrid. Renew. Sustain. Energy Rev. 2018, 82, 3670-3682. [CrossRef]

37. Dam, D.H.; Lee, H.H. An adaptive power distributed control method to ensure proportional load power sharing in DC microgrid considering equivalent line impedances. In Proceedings of the 2016 IEEE Energy Conversion Congress and Exposition (ECCE), Milwaukee, WI, USA, 18-22 September 2016. [CrossRef]

38. Papadimitriou, C.N.; Zountouridou, E.I.; Hatziargyriou, N.D. Review of hierarchical control in DC microgrids. Electr. Power Syst. Res. 2015, 122, 159-167. [CrossRef]

39. Jena, S.; Padhy, N.P.; Guerrero, J.M. Decentralized Primary and Distributed Secondary Control for Current Sharing and Voltage Regulation in DC Microgrid Clusters with HESS. In Proceedings of the 2020 IEEE International Conference on Power Electronics, Drives and Energy Systems (PEDES), Jaipur, India, 16-19 December 2020. [CrossRef]

40. Eisapour-Moarref, A.; Kalantar, M.; Esmaili, M. Power sharing in hybrid microgrids with multiple DC subgrids. Int. J. Electr. Power Energy Syst. 2021, 128, 106716. [CrossRef]

41. Lagudu, J.; Sathya Narayana, S.; Vulasala, G. Power sharing scheme in interconnected DC microgrids-A new approach. Int. J. Ambient. Energy 2020, 1-12. [CrossRef]

42. Wu, C.; Hou, X.; Wang, Y.; Chen, X.; Liao, C. SOC-featured Distributed Tertiary Control for Energy Management in DC Microgrid Clusters. In Proceedings of the 2019 22nd International Conference on Electrical Machines and Systems (ICEMS), Harbin, China, 11-14 August 2019. [CrossRef]

43. Bharath, K.R.; Krishnan, M.M.; Kanakasabapathy, P. A review on DC microgrid control techniques, applications and trends. Int. J. Renew. Energy Res. 2019, 9, 1328-1338. 
44. Dragičević, T.; Lu, X.; Vasquez, J.C.; Guerrero, J.M. DC Microgrids-Part I: A Review of Control Strategies and Stabilization Techniques. IEEE Trans. Power Electron. 2016, 31, 4876-4891. [CrossRef]

45. Dragičević, T.; Lu, X.; Vasquez, J.C.; Guerrero, J.M. DC Microgrids-Part II: A Review of Power Architectures, Applications, and Standardization Issues. IEEE Trans. Power Electron. 2016, 31, 3528-3549. [CrossRef]

46. Sahoo, S.K.; Sinha, A.K.; Kishore, N.K. Control Techniques in AC, DC, and Hybrid AC-DC Microgrid: A Review. IEEE J. Emerg. Sel. Top. Power Electron. 2018, 6, 738-759. [CrossRef]

47. Bandeiras, F.; Pinheiro, E.; Gomes, M.; Coelho, P.; Fernandes, J. Review of the cooperation and operation of microgrid clusters. Renew. Sustain. Energy Rev. 2020, 133, 110311. [CrossRef]

48. Han, Y.; Zhang, K.; Li, H.; Coelho, E.A.A.; Guerrero, J.M. MAS-Based Distributed Coordinated Control and Optimization in Microgrid and Microgrid Clusters: A Comprehensive Overview. IEEE Trans. Power Electron. 2018, 33, 6488-6508. [CrossRef]

49. Alam, M.N.; Chakrabarti, S.; Ghosh, A. Networked Microgrids: State-of-the-Art and Future Perspectives. IEEE Trans. Ind. Inform. 2019, 15, 1238-1250. [CrossRef]

50. Shafiee, Q.; Dragičević, T.; Vasquez, J.C.; Guerrero, J.M. Hierarchical control for multiple DC-microgrids clusters. IEEE Trans. Energy Convers. 2014, 29, 922-933. [CrossRef]

51. Samende, C.; Gao, F.; Bhagavathy, S.M.; McCulloch, M. Decentralized Voltage Control for Efficient Power Exchange in Interconnected DC Clusters. IEEE Trans. Sustain. Energy 2021, 12, 103-115. [CrossRef]

52. Konar, S.; Ghosh, A. Interconnection of islanded DC microgrids. In Proceedings of the Asia-Pacific Power and Energy Engineering Conference, APPEEC, Brisbane, Australia, 15-18 November 2015. [CrossRef]

53. Li, X.; Guo, L.; Li, Y.; Hong, C.; Zhang, Y.; Guo, Z.; Huang, D.; Wang, C. Flexible Interlinking and Coordinated Power Control of Multiple DC Microgrids Clusters. IEEE Trans. Sustain. Energy 2018, 9, 904-915. [CrossRef]

54. Ma, J.; Zhu, M.; Cai, X.; Li, Y.W. Configuration and operation of DC microgrid cluster linked through DC-DC converter. In Proceedings of the 2016 IEEE 11th Conference on Industrial Electronics and Applications (ICIEA), Hefei, China, 5-7 June 2016. [CrossRef]

55. Lee, M.; Choi, W.; Kim, H.; Cho, B.H. Operation schemes of interconnected DC microgrids through an isolated bi-directional DC-DC converter. In Proceedings of the 2015 IEEE Applied Power Electronics Conference and Exposition (APEC), Charlotte, NC, USA, 15-19 March 2015. [CrossRef]

56. Singh, P.; Lather, J.S. Accurate power-sharing, voltage regulation, and SOC regulation for LVDC microgrid with hybrid energy storage system using artificial neural network. Int. J. Green Energy 2020, 17, 756-769. [CrossRef]

57. Kumar, G.V.; Kaliannan, P.; Padmanaban, S.; Holm-Nielsen, J.B.; Blaabjerg, F. Effective management system for solar PV using real-time data with hybrid energy storage system. Appl. Sci. 2020, 10, 1108. [CrossRef]

58. Saraswathi, K.T.; Swaminathan, G.V.; Periasamy, S. Hybrid power management for DC microgrid cluster. Electr. Power Syst. Res. 2021, 199, 107454. [CrossRef]

59. Shahraeini, M.; Javidi, M.H.; Ghazizadeh, M.S. Comparison between communication infrastructures of centralized and decentralized wide area measurement systems. IEEE Trans. Smart Grid 2011, 2, 206-211. [CrossRef]

60. Zaery, M.; Wang, P.; Lu, X.; Wang, W.; Xu, D. Fully Distributed Controller for Economic Load Sharing of DC Microgrid Clusters. In Proceedings of the 2020 IEEE Applied Power Electronics Conference and Exposition (APEC), New Orleans, LA, USA, 15-19 March 2020. [CrossRef]

61. Li, Y.; Dong, P.; Liu, M.; Yang, G. A distributed coordination control based on finite-time consensus algorithm for a cluster of dc microgrids. IEEE Trans. Power Syst. 2019, 34, 2205-2215. [CrossRef]

62. Park, G.C.; Lee, W.P.; Won, D.J. Power Sharing Algorithm for Voltage Regulation in Islanded DC Multi-Microgrid System. In Proceedings of the 2018 53rd International Universities Power Engineering Conference (UPEC), Glasgow, UK, 4-7 September 2018. [CrossRef]

63. Reddy, G.S.; Mini, V.P.; Mayadevi, N.; Kumar, R.H. Optimal Energy Sharing in Smart DC Microgrid Cluster. In Proceedings of the 2020 IEEE International Conference on Power Electronics, Smart Grid and Renewable Energy (PESGRE2020), Cochin, India, 2-4 January 2020. [CrossRef]

64. Keshta, H.E.; Saied, E.M.; Malik, O.P.; Bendary, F.M.; Ali, A.A. Fuzzy PI controller-based model reference adaptive control for voltage control of two connected microgrids. IET Gener. Transm. Distrib. 2021, 15, 602-618. [CrossRef]

65. Chinea-Herranz, J.A.; Rodriguez, M. Control of integrated unit operations. Comput. Aided Chem. Eng. 2012, 31, 325-329. [CrossRef]

66. Ren, L. Coordinated control stategy for DC microgrid clusters considering intelligent power allocation. In Proceedings of the 2017 IEEE Conference on Energy Internet and Energy System Integration, EI2 2017, Beijing, China, 26-28 November 2017. [CrossRef]

67. Adhikari, S.; Xu, Q.; Tang, Y.; Wang, P.; Li, X. Decentralized control of two DC microgrids interconnected with tie-line. J. Mod. Power Syst. Clean Energy 2017, 5, 599-608. [CrossRef]

68. Luo, Z.; Geng, H.; Zhu, G. Hierarchical Cooperative Control for Islanded DC Microgrid Cluster *note: Sub-titles are not captured in Xplore and should not be used. In Proceedings of the 2018 IEEE International Power Electronics and Application Conference and Exposition (PEAC), Shenzhen, China, 4-7 November 2018. [CrossRef]

69. Sanjeev, P.; Padhy, N.P.; Agarwal, P. Autonomous Power Control and Management between Standalone DC Microgrids. IEEE Trans. Ind. Inform. 2018, 14, 2941-2950. [CrossRef] 
70. Kirtane, P.S.; Shendge, A.D. Control and Management of Autonomous Power between Standalone DC Microgrids. In Proceedings of the 2019 International Conference on Communication and Electronics Systems (ICCES), Coimbatore, India, 17-19 July 2019. [CrossRef]

71. Nasir, M.; Jin, Z.; Khan, H.A.; Zaffar, N.A.; Vasquez, J.C.; Guerrero, J.M. A Decentralized Control Architecture Applied to DC Nanogrid Clusters for Rural Electrification in Developing Regions. IEEE Trans. Power Electron. 2019, 34, 1773-1785. [CrossRef]

72. Han, R.; Tucci, M.; Martinelli, A.; Guerrero, J.M.; Ferrari-Trecate, G. Plug-and-Play Voltage/Current Stabilization DC Microgrid Clusters with Grid-Forming/Feeding Converters. In Proceedings of the American Control Conference, Milwaukee, WI, USA, 27-29 June 2018. [CrossRef]

73. Shafiee, Q.; Dragicevic, T.; Andrade, F.; Vasquez, J.C.; Guerrero, J.M. Distributed consensus-based control of multiple DCmicrogrids clusters. In Proceedings of the IECON 2014-40th Annual Conference of the IEEE Industrial Electronics Society, Dallas, TX, USA, 29 October-1 November 2014. [CrossRef]

74. Shahbazi, M.; Kazemtabrizi, B.; Dent, C. Coordinated control of DC voltage magnitudes and state of charges in a cluster of DC microgrids. In Proceedings of the 2016 IEEE PES innovative smart grid technologies conference Europe (ISGT-Europe), Ljubljana, Slovenia, 9-12 October 2016. [CrossRef]

75. Moayedi, S.; Davoudi, A. Cooperative power management in DC microgrid clusters. In Proceedings of the 2015 IEEE First International Conference on DC Microgrids (ICDCM), Atlanta, GA, USA, 7-10 June 2015. [CrossRef]

76. Amini, M.H.; Boroojeni, K.G.; Dragičević, T.; Nejadpak, A.; Iyengar, S.S.; Blaabjerg, F. A comprehensive cloud-based real-time simulation framework for oblivious power routing in clusters of DC microgrids. In Proceedings of the 2017 IEEE Second International Conference on DC Microgrids (ICDCM), Nuremburg, Germany, 27-29 June 2017. [CrossRef]

77. Lu, X.; Lai, J. Distributed Cluster Cooperation for Multiple DC MGs over Two-Layer Switching Topologies. IEEE Trans. Smart Grid 2020, 11, 4676-4687. [CrossRef]

78. Chen, Z.; Yu, X.; Xu, W.; Wen, G. Modeling and Control of Islanded DC Microgrid Clusters with Hierarchical Event-Triggered Consensus Algorithm. IEEE Trans. Circuits Syst. I Regul. Pap. 2021, 68, 376-386. [CrossRef]

79. Liu, R.; Liu, S.; Zheng, J.; Fang, W.; Liu, X. Function Controller Design in Tertiary Level for DC Microgrid Clusters. In Proceedings of the 2020 IEEE 9th International Power Electronics and Motion Control Conference (IPEMC2020-ECCE Asia), Nanjing, China, 29 November-2 December 2020. [CrossRef]

80. Zaery, M.; Wang, P.; Wang, W.; Xu, D. Distributed Finite-Time Controller for Economic Operation of DC Multi-Microgrids. In Proceedings of the IECON Proceedings (Industrial Electronics Conference), Lisbon, Portugal, 14-17 October 2019. [CrossRef]

81. Zaery, M.; Wang, P.; Wang, W.; Xu, D. A novel fully distributed fixed-time optimal dispatch of DC multi-microgrids. Int. J. Electr. Power Energy Syst. 2021, 129, 106792. [CrossRef]

82. Jena, S.; Padhy, N.P.; Guerrero, J.M. Cyber-Resilient Cooperative Control of DC Microgrid Clusters. IEEE Syst. J. 2021, 1-12. [CrossRef]

83. Meng, L.; Dragicevic, T.; Vasquez, J.C.; Guerrero, J.M.; Perez, J.R. Modeling and sensitivity analysis of consensus algorithm based distributed hierarchical control for DC microgrids. In Proceedings of the IEEE Applied Power Electronics Conference and Exposition-APEC, Charlotte, NC, USA, 15-19 March 2015. [CrossRef]

84. Yao, Y.; Ertugrul, N. An overview of hierarchical control strategies for microgrids. In Proceedings of the 2019 29th Australasian Universities Power Engineering Conference (AUPEC), Nadi, Fiji, 26-29 November 2019. [CrossRef]

85. Han, R.; Tucci, M.; Martinelli, A.; Guerrero, J.M.; Ferrari-Trecate, G. Stability Analysis of Primary Plug-and-Play and Secondary Leader-Based Controllers for DC Microgrid Clusters. IEEE Trans. Power Syst. 2019, 34, 1780-1800. [CrossRef]

86. Mingsheng, Z.; Peilei, F.; Hesong, W.; Wenkui, W.; Pengcheng, C. Hierarchical Control Strategy for Microgrid. In Proceedings of the 2018 2nd IEEE Advanced Information Management, Communicates, Electronic and Automation Control Conference (IMCEC), Xi'an, China, 25-27 May 2018. [CrossRef]

87. Zaery, M.; Wang, P.; Wang, W.; Xu, D. Distributed Global Economical Load Sharing for a Cluster of DC Microgrids. IEEE Trans. Power Syst. 2020, 35, 3410-3420. [CrossRef]

88. Lu, X.; Li, Q. Two-Layer Discrete-Time Iterative Cooperation for Interconnected DC Microgrids. In Proceedings of the IECON Proceedings (Industrial Electronics Conference), Singapore, Singapore, 18-21 October 2020. [CrossRef]

89. Yilin, L.I.; Ping, D.O.N.G. A distributed control based on finite-time consensus algorithm for the cluster of DC microgrids. In Proceedings of the 2018 International Conference on Power System Technology (POWERCON), Guangzhou, China, 6-8 November 2018. [CrossRef]

90. Fu, Y.; Zhang, Z.; Mi, Y.; Li, Z.; Li, F. Droop Control for DC Multi-Microgrids Based on Local Adaptive Fuzzy Approach and Global Power Allocation Correction. IEEE Trans. Smart Grid 2018, 10, 5468-5478. [CrossRef]

91. Wu, P.; Huang, W.; Tai, N.; Ma, Z.; Zheng, X.; Zhang, Y. A multi-layer coordinated control scheme to improve the operation friendliness of grid-connected multiple microgrids. Energies 2019, 12, 255. [CrossRef]

92. Shafiee, Q.; Dragicevic, T.; Vasquez, J.C.; Guerrero, J.M. Modeling, stability analysis and active stabilization of multiple DCmicrogrid clusters. In Proceedings of the 2014 IEEE international energy conference (ENERGYCON), Cavtat, Croatia, 13-16 May 2014. [CrossRef]

93. Dragičević, T.; Guerrero, J.M.; Vasquez, J.C.; Škrlec, D. Supervisory control of an adaptive-droop regulated DC microgrid with battery management capability. IEEE Trans. Power Electron. 2014, 29, 695-706. [CrossRef] 
94. Lu, X.; Sun, K.; Guerrero, J.M.; Vasquez, J.C.; Huang, L. State-of-charge balance using adaptive droop control for distributed energy storage systems in DC microgrid applications. IEEE Trans. Ind. Electron. 2014, 61, 2804-2815. [CrossRef]

95. Sahoo, S.; Mishra, S.; Fazeli, S.M.; Li, F.; Dragičević, T. A Distributed fixed-Time secondary controller for dc microgrid clusters. IEEE Trans. Energy Convers. 2019, 34, 1997-2007. [CrossRef]

96. Tu, C.; Xiao, F.; Lan, Z.; Guo, Q.; Shuai, Z. Analysis and Control of a Novel Modular-Based Energy Router for DC Microgrid Cluster. IEEE J. Emerg. Sel. Top. Power Electron. 2019, 7, 331-342. [CrossRef]

97. Li, Z.; Duan, Z. Cooperative Control of Multi-Agent Systems: A Consensus Region Approach; CRC Press: Boca Raton, FL, USA, 2017. [CrossRef]

98. Zhou, Q.; Shahidehpour, M.; Paaso, A.; Bahramirad, S.; Alabdulwahab, A.; Abusorrah, A. Distributed Control and Communication Strategies in Networked Microgrids. IEEE Commun. Surv. Tutor. 2020, 22, 2586-2633. [CrossRef]

99. Guo, F.; Wen, C.; Mao, J.; Song, Y.D. Distributed Economic Dispatch for Smart Grids with Random Wind Power. IEEE Trans. Smart Grid 2016, 7, 1572-1583. [CrossRef]

100. Lu, X.; Lai, J.; Yu, X.; Wang, Y.; Guerrero, J.M. Distributed coordination of islanded microgrid clusters using a two-layer intermittent communication network. IEEE Trans. Ind. Inform. 2018, 14, 3956-3969. [CrossRef]

101. Faraji, J.; Ketabi, A.; Hashemi-Dezaki, H.; Shafie-Khah, M.; Catalao, J.P. Optimal day-ahead self-scheduling and operation of prosumer microgrids using hybrid machine learning-based weather and load forecasting. IEEE Access 2020, 8, 83561-83582. [CrossRef] 